\title{
Article \\ Durability and Safety Performance of Pavements with Added Photocatalysts
}

\author{
Eva Jimenez-Relinque (D), Maria Grande, Francisco Rubiano and Marta Castellote *(D) \\ Institute of Construction Science, Spanish National Research Council, "Eduardo Torroja” (IETcc-CSIC), \\ C/Serrano Galvache 4, 28033 Madrid, Spain; eva.jimenez@csic.es (E.J.-R.); M.grande@ietcc.csic.es (M.G.); \\ franrs12@ietcc.csic.es (F.R.) \\ * Correspondence: Martaca@ietcc.csic.es
}

Citation: Jimenez-Relinque, E.; Grande, M.; Rubiano, F.; Castellote, M. Durability and Safety Performance of Pavements with Added Photocatalysts. Appl. Sci. 2021, 11, 11277. https://doi.org/10.3390/ app112311277

Academic Editors: Jiaqi Chen, Kezhen Yan and Jun Xie

Received: 27 October 2021

Accepted: 22 November 2021

Published: 29 November 2021

Publisher's Note: MDPI stays neutral with regard to jurisdictional claims in published maps and institutional affiliations.

Copyright: (C) 2021 by the authors Licensee MDPI, Basel, Switzerland. This article is an open access article distributed under the terms and conditions of the Creative Commons Attribution (CC BY) license (https:// creativecommons.org/licenses/by/ $4.0 /)$.
Abstract: The use of photocatalysts to enhance the performance of construction materials with large surfaces exposed to sunlight has become an increasingly common practice in recent decades. Although construction material durability is of crucial importance and is extensively studied when incorporating new additions, very few studies have specifically addressed the effects when adding photocatalysts. This paper discusses the effect of $\mathrm{TiO}_{2}$-based photocatalysts on pavement durability (porosity, time of transmission of ultrasonic pulses, freeze-thaw resistance and capillary water absorption) and safety (slip resistance and roughness) by comparison of commercial photocatalytic materials of different families and twin materials without the photocatalyst added. The analysis covers concrete tile pavements and porous asphalt treated with photocatalysts in the form of sprayed emulsions, slurry admixtures or built-in during casting. The findings show that changes in the properties of a construction material induced by photocatalytic functionality depend primarily on the porous structure of the matrix and the properties of the resulting photocatalytic surface.

Keywords: $\mathrm{TiO}_{2}$; nanoparticles; photocatalytic; durability; slip resistance; pavements; asphalt; concrete

\section{Introduction}

Photocatalytic oxidation has been proposed in the last few years as a possible solution to reduce the level of air pollution. This technique was first applied to energy generation in the 1970s by Fujishima and Honda [1] and Wrighton et al. [2]. Given the huge area exposed to sunlight in construction materials, they have been one of the objects of choice of the technology for applications such as self-cleaning [3-7], decontamination [7-14], self-sterilisation [15,16], anti-fogging [17], pollen and allergen degradation [18-21] and soot elimination [22]. The photocatalytic functionality is implemented through the addition of a semi-conductor, usually nanoparticles of $\mathrm{TiO}_{2}$.

In light of the crucial importance of construction material durability, the use and effects of new components are usually extensively researched. Scientific portal Scopus reviewed for this study returned a total of 10,507 documents in a search using the keywords 'durability' and 'construction material'. Only 47 were identified when the word 'photocatalytic' was added. While some of those deal with the advantages and drawbacks of nanotechnology applied to construction materials [23-25], most address the durability and performance of photocatalytic coatings. Examples include studies of resistance to peeling and water under pressure in limestone coatings [26], leaching of the photocatalytic pavements [27], mechanical and chemical durability of photocatalysts on exposed aggregates [28], durability of self-cleaning $\mathrm{TiO}_{2}$ coatings on fired clay bricks exposed to UV radiation and wet/dry cycles [29], $\mathrm{TiO}_{2}$ coating abrasion and wear resistance and its effect on the environmental impact of the coatings [30-32], cyclic weathering in photocatalytic glass-reinforced concrete panels [33] bonding in a number of coatings [34], $\mathrm{TiO}_{2}$-cement mortar bonded to asphalt pavement with an epoxy resin [35] and durability of photocat- 
alytic activity on different cement-based materials exposed to abrasion and freeze-thaw stress [36].

Papers have also been published on the effects of $\mathrm{TiO}_{2}$ on the properties of hardened cement pastes, particularly when the photocatalyst is added during casting. $\mathrm{Nano}-\mathrm{TiO}_{2}$ has been reported to act as a catalyst in cement hydration reactions [37] and hydration and drying shrinkage [38], whilst its effect on the mechanical properties of cement mortar [39,40] and microstructure [41] have likewise been studied. Other authors have explored the impact of cement chemistry [42-44] and the behaviour in expansive concretes [45].

Very little research has been conducted on the specific effects of photocatalytic admixtures or emulsions on the durability of the construction material itself. The areas studied include chloride penetration in $\mathrm{TiO}_{2}$-additioned concretes [46] and the durability of photocatalytic concrete determined with accelerated carbonation [47]. A study of the effects of $\mathrm{TiO} 2$ nanoparticles on ordinary portland cement (OPC) and slag-blended mortar resistance to sulphate attack [48], in turn, concluded that the addition made the materials more vulnerable. Rheological properties, mechanical strength and carbonation have also been analysed [49]. All those studies were conducted on cementitious materials in which nano- $\mathrm{TiO}_{2}$ was mixed in during casting and most dealt with particulars of the effects of the photocatalyst in isolation. No comprehensive papers were found on the effect of photocatalysts on the intrinsic behaviour of construction materials related to durability and safety parameters, as slip resistance is crucial in pavements.

Both types of considerations are analysed here for different matrixes with different photocatalysts applied (porous asphalt intruded with photocatalytic slurries and sprayed with $\mathrm{TiO}_{2}$-based coatings, concrete paving tiles sprayed with emulsions and with builtin photocatalysts) in comparison with the same materials without the photocatalytic functionality. The experimental setup consists of pilot scale outdoor exposed slabs of at least $1 \mathrm{~m}^{2}$. The durability and safety tests were performed both in the lab, on cores extracted from the slabs, and on the slabs themselves.

This study has been made in the framework of the life project life-photoscaling [50]. The composition and characteristics of the photocatalysts cannot be disclosed here for confidentiality reasons. However, as the objective of this paper is the evaluation of the intrinsic effects due to the addition of the photocatalysts on the material itself, this does not devalue the interest of this research.

\section{Materials and Methods}

\subsection{Materials}

A pilot scale demonstration platform with slabs of at least $1 \mathrm{~m}^{2}$ each makes up the experimental setup. Fourteen different paving materials were used, 10 of which had photocatalytic functionality and 4 were the corresponding reference materials without the photocatalyst. They were stored outdoors at IETcc-CSIC headquarters, located in Madrid, Spain. The photoactive material in all of them was a $\mathrm{TiO}_{2}$-based photocatalyst, and several configurations were chosen to cover the main commercially available photocatalytic solutions in construction materials. This includes in-situ applications of slurries and emulsions over two different matrixes: open-graded asphalt (24.6 percent of air voids as measured by UNE-EN 12697-08:200) and/or urban concrete tiles), as well as tiles in which the photocatalyst was incorporated when casting. The emulsion coatings were sprayed on both asphalt and tiles, the cementitious slurries were spread on open asphalt substrate using a cleaner wiper, and the photocatalytic tiles were glued to a concrete basis. All of them were applied by the producers of the materials or by staff of the IETcc following the instructions given by the producers. More details on the experimental setup configuration are given in $[14,27,51]$.

Table 1 shows the labelling of the materials, as well as their initial efficiency in NOx degradation (RNOx (\%)) measured on laboratory samples according to ISO 22197-1:2007. 
Table 1. Material description and labels.

\begin{tabular}{|c|c|c|c|}
\hline Substrate & Commercial Photocatalytic Material & Initial RNOx (\%) & Label \\
\hline \multirow{6}{*}{ Asphalt (A) } & - & - & Ref-A \\
\hline & Slurry 1 & 26.91 & S1-A \\
\hline & Slurry 2 & 7.22 & S2-A \\
\hline & Emulsion 1 & 2.78 & E1-A \\
\hline & Emulsion 2 & 6.36 & E2-A \\
\hline & Emulsion 3 & 13.63 & E3-A \\
\hline \multirow{4}{*}{ Paving tile $(\mathrm{T})$} & - & - & Ref-T \\
\hline & Emulsion 1 & 10.84 & E1-T \\
\hline & Emulsion 2 & 18.97 & $\mathrm{E} 2-\mathrm{T}$ \\
\hline & Emulsion 3 & 29.71 & E3-T \\
\hline Untreated paving tile 1 & - & - & Ref-T1 \\
\hline Paving tile 1 & Incorporated in tile & 4.6 & $\mathrm{~T} 1$ \\
\hline Untreated paving tile 2 & - & - & Ref-T2 \\
\hline Paving tile 2 & Incorporated in tile & 22.93 & $\mathrm{~T} 2$ \\
\hline
\end{tabular}

\subsection{Methods}

\subsubsection{Characterization}

The asphalt (Ref-A) and the paving tile (Ref-T) references were fully characterised for physical-chemical and mechanical properties. The characteristics of the untreated precast paving tiles likewise used as references (Ref-T1 and Ref-T2) cannot be disclosed for reasons of industrial confidentiality. The penetration of the slurries into the porous asphalt, the layer depths formed after deposition of the emulsions of photocatalysts and the distribution of the $\mathrm{TiO}_{2}$ in the already incorporated tiles were studied after three months by Backscattered Scanning Electron Microscopy (BSE) coupled to an Energy Dispersive Spectroscopy (EDS) detector.

Porosity, pore size distribution and density were determined by mercury intrusion porosimetry (MIP) on $1 \times 1 \times 1 \mathrm{~cm}$ samples. The mercury was intruded across the surface layer with a Micromeritics porosimeter at a contact angle of $130^{\circ}$ and a penetrometer constant of $10.79 \mu \mathrm{L} / \mathrm{pF}$. The pulse velocity for concrete and paving materials defined in ASTM C597 was used to assess ultrasonic pulse transmission time. Measurements were conducted using the indirect procedure, positioning the transducers directly on slab substrates with the inner ends spaced at $10 \mathrm{~cm}$.

\subsubsection{Freeze-Thaw Resistance}

In order to evaluate the freeze-thaw resistance, a modified version of the test described in CEN/TR 15177:2006 was applied. In this method, specimens are exposed to freeze-thaw cycles with demineralised water as the freezing medium. The modifications introduced relative to the standard procedure primarily affect specimen size, casting and conditioning. The tests were conducted on approximately $15 \times 8 \mathrm{~cm}$ cores removed from the outdoor exposed slab materials. All but the test surfaces of the specimens were sheathed in rubber secured to the material with silicone. The top edge of the rubber sheath protruded $20 \pm 1 \mathrm{~mm}$ over the test surface. The sheathed samples were pre-saturated for 3 days. The test surface of the paving tiles was covered with a mean $3 \mathrm{~mm}$ deep layer of liquid protected from evaporation with a thick polyethylene film. In the asphalt samples, as the liquid water seeped into the specimen rather than remaining on the surface, a soaked sponge positioned on the surface of the cores was used as the freezing medium. The specimens were insulated with white cork on all but the test surfaces (Figure 1a). 


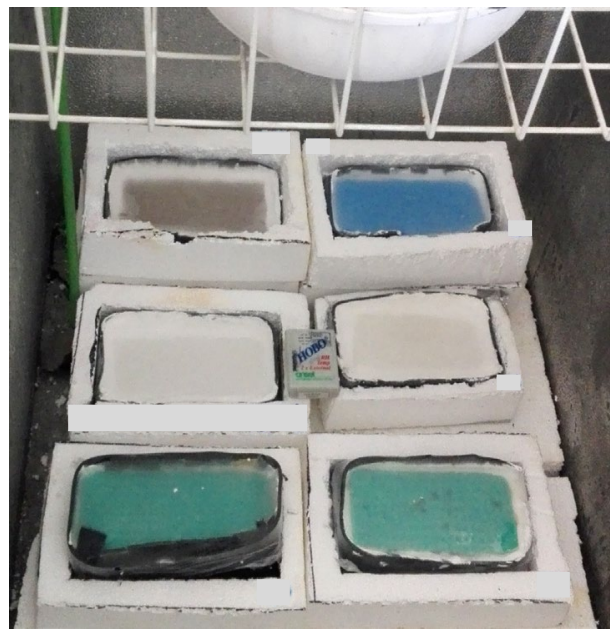

(a)

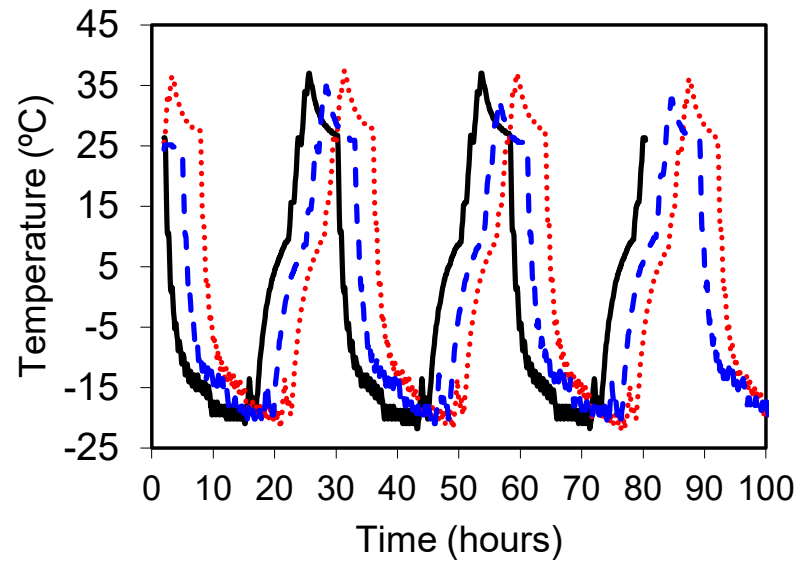

(b)

Figure 1. (a) Freeze-thaw resistance test setup and (b) freeze-thaw temperatures of 3 different cycles.

After 3 days of preconditioning prior to freezing, water was removed from the specimen surfaces and the first ultrasonic reading, defined as the reference value, was taken. Since some of the samples were so narrow that the ultrasonic sensors protruded beyond the sides of the specimen, readings were taken with the sensors spaced at $4 \mathrm{~cm}$ on the active surface. The specimens were subsequently exposed to successive freeze-thaw cycles. During thawing, air temperatures of up to $35^{\circ} \mathrm{C}$ were reached, for such values are readily reached in the air in Madrid in summer. The temperature of the freezing medium at the centre of the test surface was continuously recorded on one specimen in each freezing chamber. The data for three cycles are graphed in Figure 1b. The excess freezing medium was poured off and the scaled material collected after 7, 14, 28, 42 and 56 cycles. The ultrasonic pulse transmission times (UPTT) were then measured, the scaled material was weighed, and new freezing medium was poured onto the test surface, or the sponge was replaced, before returning the samples to the freezing chamber. The results were assessed against RILEM TC 176-IDC [52], calculating relative UPTT, $\gamma$, as defined in Equation (1):

$$
\gamma=\left(\frac{t_{n}}{t_{0}}\right) \times 100
$$

where $t_{n}$ is the transmission time measured after $i$ freeze-thaw cycles $(\mu s)$ and $t_{0}$ the initial transmission time ( $\mu \mathrm{s})$.

The RILEM classification of concrete by relative UPTT is listed in Table 2. As explained in the aforementioned publication, the damage levels given in the table should not be mistaken for acceptance criteria.

Table 2. Concrete classification by relative UPTT $(\gamma)$ [52].

\begin{tabular}{lllll}
\hline Relative UPTT, $\gamma$ & $<100 \%$ & $100 \% \sim 110 \%$ & $110 \% \sim 120 \%$ & $>120 \%$ \\
\hline Test finding & Not deteriorated & $\begin{array}{l}\text { Possibly } \\
\text { deteriorated }\end{array}$ & Deteriorated & $\begin{array}{l}\text { Severely } \\
\text { deteriorated }\end{array}$ \\
\hline Resistance class & Good & Intermediate & Poor & Very poor \\
\hline
\end{tabular}

\subsubsection{Capillary Water Absorption}

A modified version of the Fagerlund method [53] was used. The test specimens were preconditioned to an equilibrium moisture of around $75 \% \mathrm{RH}$ with a saturated $\mathrm{NaCl}$ solution. All but one of the surfaces were sealed with self-adhesive tape to prevent the penetration of water vapour into the test specimens during the absorption experiment. The specimens were weighed to an accuracy of $0.1 \mathrm{~g}$ immediately prior to testing. The unsealed 
side of the samples (the coated surface in the sprayed photocatalytic specimens) was positioned on the surface of the water (instead of being soaked in the medium to a depth of $5 \mathrm{~mm}$ as specified in the method) in light of the scant depth of some of the specimens. Water was added throughout the duration of the test to offset evaporation. Capillary absorption-induced water intake was measured by periodically weighing the specimens until weight remained constant. The surface in contact with the water was wiped with a moist sponge or non-absorbent cloth to remove excess water prior to weighing. Data for T1 and Ref-T1 are not available as they were too thin to be tested $(1 \mathrm{~cm}$ depth).

The mass of water absorbed vs. square root of time curves exhibited two different trends, one ascending, indicative of absorption, and the other flat, denoting saturation. The parameters associated with capillary absorption $(m$, resistance to water penetration $\left(\mathrm{s} / \mathrm{m}^{2}\right) ; k$, the capillary absorption coefficient $\left(\mathrm{kg} / \mathrm{m}^{2} \cdot \mathrm{s}^{0.5}\right)$; and $\varepsilon_{e}$, effective porosity) were calculated from these curves.

\subsubsection{Slip Resistance (Standard EN-14231) and Surface Roughness}

Slip resistance was determined on all the slab surfaces analysed with a pendulum tester as described in standard EN-14231. Slip resistance is closely related to surface roughness [54]. Three-D surface roughness profiles for all the materials studied were generated from photographs with ImageJ software [55]. The pixel values represent the distance or depth into the coating. Roughness parameter $R a$ (pixels) was subsequently calculated from the roughness profiles with Equation (2) [56]:

$$
R_{a}=\frac{1}{n_{x} n_{y}} \sum_{i=1}^{n_{x}} \sum_{j=1}^{n_{y}}\left|Z(i, j)-Z_{\text {ave }}\right|
$$

where $Z(i, j)$ represents the surface topography after image tilt-correction (surface-levelling), $Z_{\text {ave }}$ is mean surface height, $i$ is intensity in pixels in the $x$ direction and $j$ in the $y$ direction, $n_{x}$ is maximum number of pixels in the $x$ direction and $n_{y}$ in the $y$ direction.

\section{Results}

\subsection{Characterization}

The results corresponding to the characterisation of Ref-A and Ref-T are given in Tables 3 and 4, respectively.

Table 3. Physico-chemical and mechanical characteristics of the asphalt (Ref-A).

\begin{tabular}{ll}
\hline Parameter & Value \\
Procedure or Standard & 4.9 \\
\hline Bitumen binder referred to total mix (\%) & 5.1 \\
Bitumen binder referred to aggregate $(\%)$ & $18.4 /$ porphyry \\
Gravel $6 \mathrm{~mm}-12 \mathrm{~mm}(\%) /$ type of aggregate & $76.7 /$ limestone-based \\
Sand 0 mm-2 mm (\%)/type of aggregate & $3.9 /$ limestone-based \\
Filler-Contribution $(\%) /$ type of aggregate & $1 /$ limestone and siliceous-based \\
Filler-Recovering $(\%) /$ type of aggregate & 4.25 \\
Soluble bitumen binder content referred to total mix $(\%)$ & \\
Centrifuge extraction & 4.44 \\
Soluble bitumen binder content-aggregate $(\%)$ & \\
Centrifuge extraction & 0.79 \\
Filler/bitumen binder ratio & \\
Centrifuge extraction & 4.25 \\
Bitumen binder content $(\%)$ & 1.03 \\
UNE EN 12697-6:2003 & \\
Bitumen binder density $\left(\mathrm{g} / \mathrm{m}^{3}\right)$ & 24.6 \\
UNE EN 12697-6:2003 & \\
Air voids & \\
UNE EN 12697-08:2008 & \\
\hline
\end{tabular}


Table 3. Cont.

\begin{tabular}{ll}
\hline $\begin{array}{l}\text { Parameter } \\
\text { Procedure or Standard }\end{array}$ & Value \\
\hline Bitumen binder-filled voids & 32.5 \\
UNE EN 12697-08:2008 & \\
Aggregate-filled voids & 24.16 \\
UNE EN 12697-08:2008 & 394.68 \\
Compressive strength (kPa) & 82.3 \\
Indirect tensile strength ratio (ITSR) (\%) & 0.049 \\
Air WTS * (rolling) (\%) & 17.802 \\
Air PRD ** (rolling) (\%) & 10.681 \\
RD (rolling) (mm) & 91.4 \\
Particle loss (\%) & \\
UNE EN 12697-17:2006+A1:2007 & \\
\hline *Wheel tracking slope*** Proportional rutting depth.
\end{tabular}

Table 4. Physicochemical characteristics of the concrete paving tiles (Ref-T).

\begin{tabular}{ll}
\hline $\begin{array}{l}\text { Parameter } \\
\text { Procedure or Standard }\end{array}$ & Results \\
\hline $\begin{array}{l}\text { Length (mm) } \\
\text { UNE EN 1339:2003 }\end{array}$ & 150 \\
Width (mm) & 10 \\
UNE EN 1339:2003 & 33 \\
Thickness (mm) & \\
UNE EN 1339:2003 & 8.3 \\
Bending strength (MPa) & 8995 \\
UNE EN 1339:2003 & \\
Failure load (N) & $>1000$ \\
UNE EN 1339:2003 & \\
Height of first fissure (mm) & 800 \\
UNE EN 127748-2:2006 & \\
Height of failure point (mm) & 70.0 \\
UNE EN 127748-2:2006 & \\
Abrasion test track length (mm) & 15.5 \\
UNE EN 1339:2004 & \\
Abrasion test track width (mm) & \\
UNE EN 1339:2004 &
\end{tabular}

Figure 2a shows BSE images of the different materials with the corresponding elemental mapping images for $\mathrm{Ti}$, for each of the photocatalytic materials. Images for E1-A, E2-A and E3-A are not given as no Ti could be detected in the transversal cut after 3 months of the application.

In Figure 2a it can be seen that the sample Ref-A presents high open porosity, in agreement with the results in Table 3 (24.6\% of air voids). With the photocatalytic slurries embedded, the area of penetration gets much more compact. In the case of S1-A the compaction layer is present throughout the sample's surface with non-homogeneous depth, having found denser layers with high amount of Ti between $25 \mu \mathrm{m}$ and $150 \mu \mathrm{m}$. The mean penetration of the slurries has been (naked eye measurement) around 7 and $5 \mathrm{~mm}$ (see Figure 2b) for S1-A and S2-A respectively. When looking at the BSE transversal cut of the samples E1-A, E2-A and E3-A, no Ti could be detected (not shown in Figure 2), having equivalent images than those of Ref-A. As expected, reference tiles (Ref-T) exhibited a more compact aspect, typical of a precast concrete. When applying the photocatalytic emulsions, the distribution and conformation of the layers is different for the different photocatalysts. E1-T presents a quite irregular, and in some parts discontinuous, layer on the surface, with an average of $3.7 \mu \mathrm{m}$ and a standard deviation of $2.2 \mu \mathrm{m}$. No Ti has penetrated the sample. E2-T presents a different feature. There is not a well-defined layer on the surface; only 
isolated spots with Ti having penetrated into the material. E3-T has formed a compact and continuous layer on the surface of the tile with an average of $5.1 \mu \mathrm{m}$ and a standard deviation of $2.4 \mu \mathrm{m}$. T1 is a very compact tile and the photocatalyst is present in a layer (average of $1.7 \mu \mathrm{m}$ and standard deviation of $0.22 \mu \mathrm{m}$ ) that is weakly bonded to the surface as during the processing of the samples for the analysis, the layer has been detached. In T2, $\mathrm{Ti}$ is present homogeneously in the bulk of the sample.
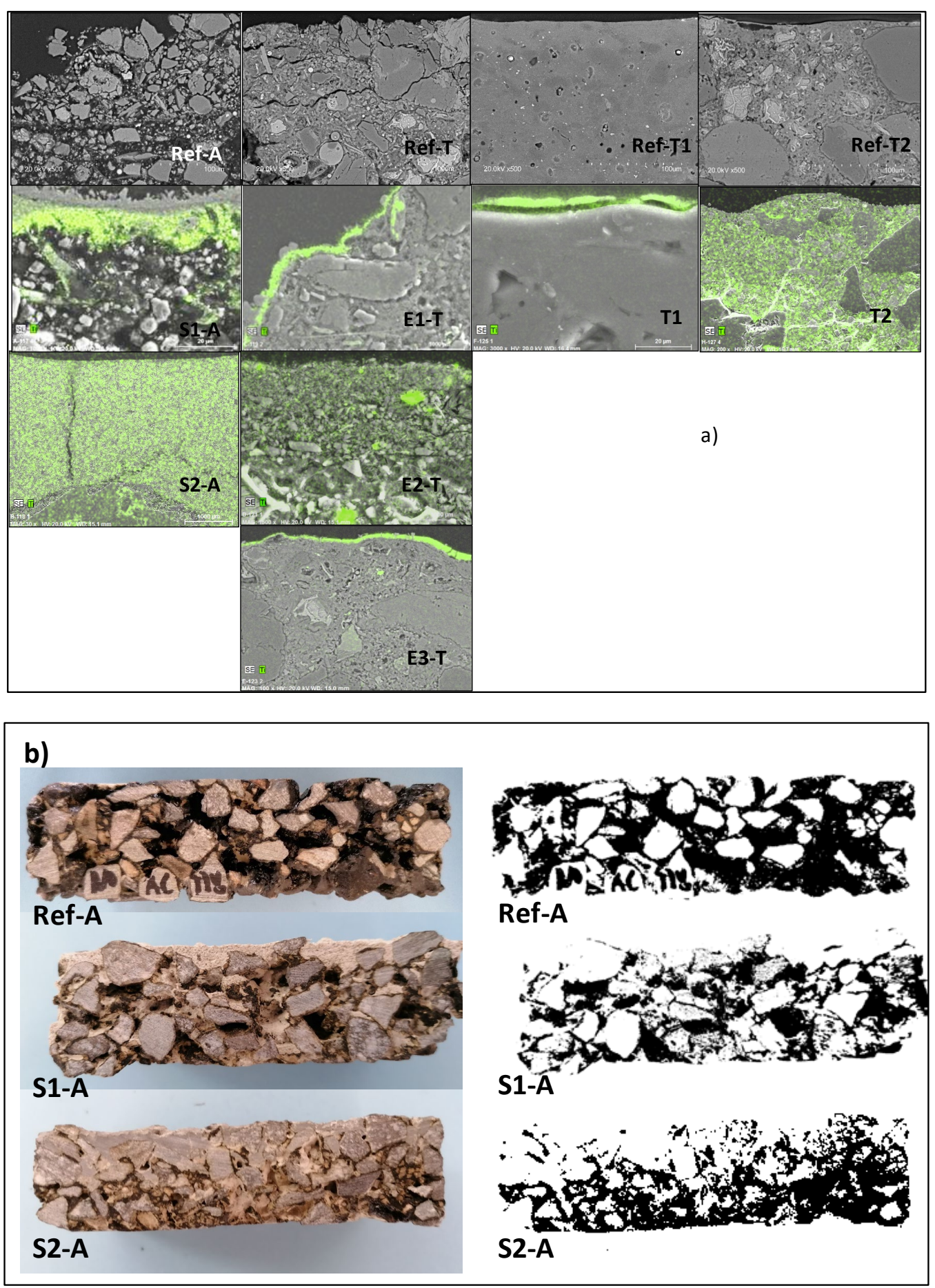

Figure 2. (a) BSE images for the reference and photocatalytic materials (with the corresponding elemental mapping images for Ti in green). Images for E1-A, E2-A and E3-A are not given as no Ti could be detected in the transversal cut. (b) Pictures of the profile reached by the slurries into the open asphalt. 


\subsection{Mercury Intrusion Porosimetry (MIP)}

Table 5 gives the MIP findings for total porosity (volume per cent), mean pore diameter ( $4 \mathrm{~V} / \mathrm{A}$ ) and matrix bulk density for pore sizes in the $400 \mu \mathrm{m}$ to $0.007 \mu \mathrm{m}$ range. Before analysing the results, it has to be considered that a cube of approximately $1 \mathrm{~cm}^{3}$ was used for MIP, intruding the $\mathrm{Hg}$ through the photocatalytic layer. Then, the results are taking into account the photocatalytic layer and the bulk of the matrix. Thus, the absolute values in Table 5 have only comparative purposes but cannot be considered as "real" values. Much more informative are the results given in Figure $3 a-d$ that presents the differential pore size distributions for the samples. Additionally, Figure 3a shows the pore sizes ranges along with their classification into both IUPAC categories [macropores $(>50 \mathrm{~nm})$, mesopores $(50 \mathrm{~nm}$ to $2 \mathrm{~nm}$ ) and micropores $(<2 \mathrm{~nm})]$ and the conventional categories for concrete [air voids $(>10 \mu \mathrm{m})$, large capillaries ( $50 \mathrm{~nm}$ to $10 \mu \mathrm{m})$, medium capillaries $(10 \mathrm{~nm}$ to $50 \mathrm{~nm}$ ) and gel pores $(<10 \mathrm{~nm})]$.

From results from MIP (Table 5) and the data in Table 2, it can be deduced that most of the porosity in the asphalt pavement lay outside the MIP pore size range being these a mere $0.73 \%$ of the total. Imbibition of the slurries filled the voids, generating a finer pore system with different pore size distributions for each of the slurries, as detected by MIP. Pore size in the S1-A peaked at around $12 \mu \mathrm{m}$ and no pores $<0.015 \mu \mathrm{m}$ were detected. Finer porosity is found in S2-A, with one of its two peaks positioned in the air voids zone while the other was wide and lay in the medium capillary pore area, at around $0.03 \mu \mathrm{m}$.

Emulsion coatings do not significantly influence the pore distribution of asphalt, almost all located in the macropores range for two of the emulsion coatings on asphalt (Figure $2 \mathrm{~b}$ ). The greater porosity in E1-A than the other emulsion asphalt samples was concentrated primarily in a (narrow peak) in the large capillary pore range. Concerning emulsions on tiles, E1-T presents a significant fraction in the air void fraction (wide peak). The rise in the fraction of mesopores (around $0.02 \mu \mathrm{m}$ ) in the three emulsion-coated paving tiles relative to the Ref-T reference might also be attributed to the emulsion. T1 exhibited nearly negligible porosity, lower even than in Ref-T1, in the range studied. The curves for Ref-T2 and T2 exhibited three modes, at $70 \mu \mathrm{m}, 1 \mu \mathrm{m}$ and $0.03 \mu \mathrm{m}$, with a predominant peak at the first value in sample T2.

Table 5. Mercury intrusion porosimetry parameters for samples (samples outside the $400 \mu \mathrm{m}$ to $0.007 \mu \mathrm{m}$ range not detected) and mean ultrasonic pulse transmission time UPTT ( $\mu$ s) between the two transducers spaced on the slab surfaces at a distance of $10 \mathrm{~cm}$.

\begin{tabular}{ccccc}
\hline Sample & Porosity (\% Vol) & $\begin{array}{c}\text { Mean Pore Diameter } \\
(\mathbf{4} \text { V/A) } \\
(\boldsymbol{\mu} \mathbf{m})\end{array}$ & $\begin{array}{c}\text { Bulk } \\
\text { Density } \\
(\mathbf{g} / \mathbf{m L})\end{array}$ & $\begin{array}{c}\text { UPTT } \\
(\boldsymbol{\mu s})\end{array}$ \\
\hline Ref-A & 0.73 & 7.337 & 2.64 & 82.8 \\
S1-A & 2.64 & 0.583 & 2.46 & 73.1 \\
S2-A & 4.92 & 0.065 & 2.28 & 47.6 \\
E1-A & 1.10 & 5.287 & 2.53 & 87.9 \\
E2-A & 0.82 & 9.403 & 2.50 & 71.0 \\
E3-A & 0.84 & 6.408 & 2.58 & 147.2 \\
\hline Ref-T & 10.75 & 0.140 & 2.25 & 44.2 \\
E1-T & 12.70 & 0.071 & 2.19 & 64.5 \\
E2-T & 8.87 & 0.072 & 2.27 & 61.9 \\
E3-T & 9.62 & 0.062 & 2.26 & 57.9 \\
\hline Ref-T1 & 0.45 & 0.948 & 2.34 & 27.0 \\
T1 & 0.24 & 0.788 & 2.37 & 16.7 \\
\hline Ref-T2 & 10.09 & 0.103 & 2.25 & 26.3 \\
T2 & 12.50 & 0.084 & 2.19 & 39.8 \\
\hline
\end{tabular}



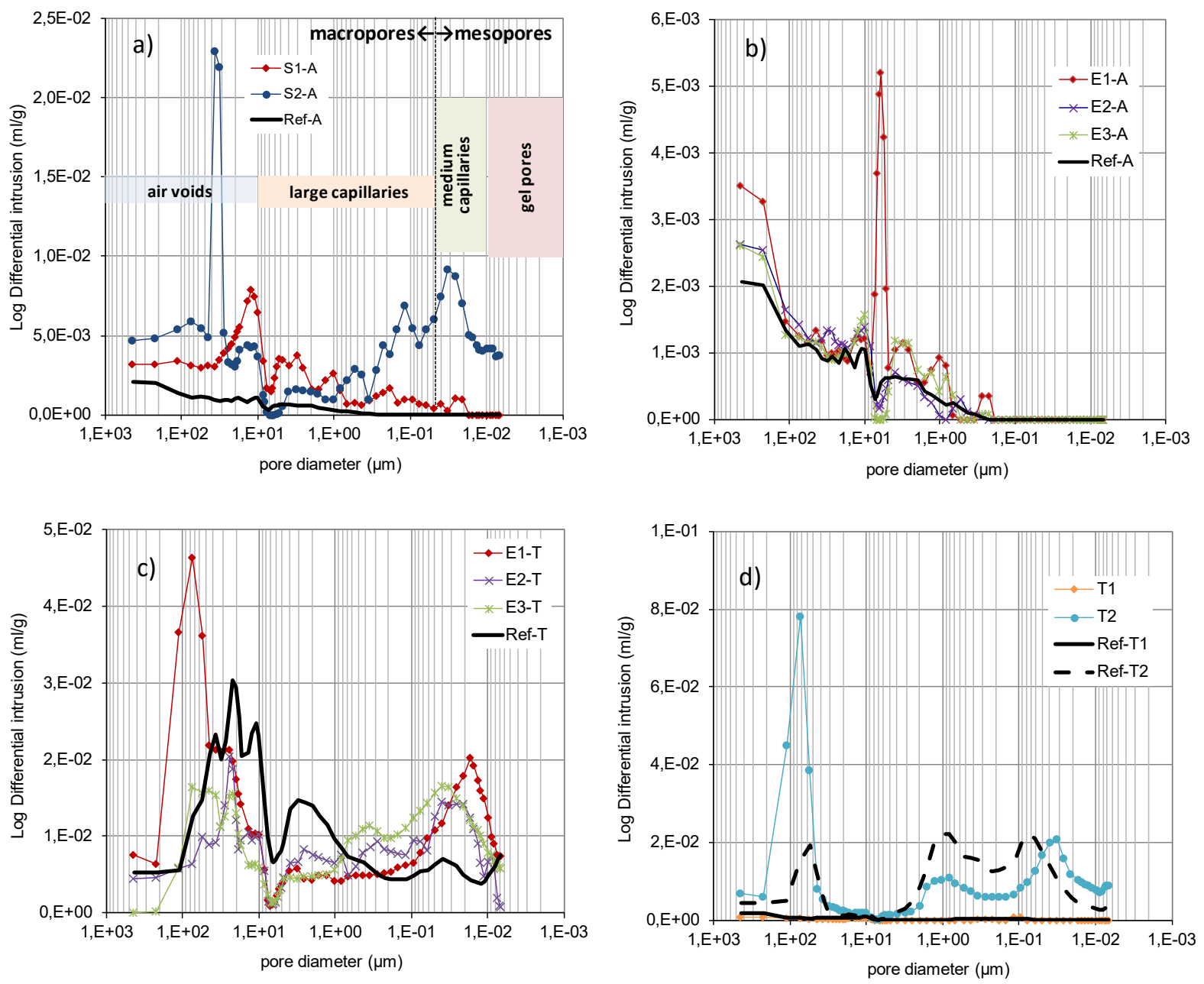

Figure 3. (a-d) Differential pore size distribution in the samples.

\subsection{Ultrasonic Pulse Transmission Time (UPTT)}

The mean ultrasonic pulse transmission time $(\mu \mathrm{s})$ between the two transducers spaced on the slab surfaces at a distance of $10 \mathrm{~cm}$ are also given in Table 5. As expected, the slurries densified materials S1-A and S2-A rendering them more compact, which translated into shorter time and then higher ultrasonic pulse velocity. No pattern could be discerned for the emulsion-coated asphalt materials, as some of the samples exhibited higher values (E1-A and especially E3-A) and some other lower values (E2-A) than the reference. The three emulsion-sprayed paving tiles and the T2 exhibited higher UPTTs than the respective references, whereas in T1 the value was lower than in Ref-T1. As noted earlier, the different tendency in the two tiles with built-in photocatalysts were attributable to the differences between their physical-chemical characteristics, loading and mode of implementation.

\subsection{Freeze-Thaw Resistance}

The relative UPTT (\%) vs. number of freeze-thaw cycle curves for asphalt samples are plotted in Figure $4 \mathrm{a}$ and for paving tiles in Figure $4 \mathrm{~b}$. All the reference samples qualified for classification as RILEM 'good' resistance materials [52]. Photocatalytic samples S2-A, E1-A, E2-A, E3-A and T2 were also so qualified, albeit with some scatter, whilst S1-A exhibited 'intermediate' resistance. The poorest performance was observed in emulsioncoated paving tiles E1-T, E2-T and E3-T, which has been attributed to the photocatalytic layer cracking. The cracks might also explain the wider scatter observed for these materials. Even though there are a small number of samples, no clear deterioration can be seen in the bulk of any of them as no continuous rise in the relative UPTT has been observed in any 
case. The apparent inconsistent decline in relative UPTT after more cycles might denote peeling away of the photocatalytic layer that makes the matrix arise in the surface. E1-T exhibited the lowest resistance of all the photocatalytic samples, followed by E3-T and T1, in that order. Scaling was detected in only four samples (Figure 5), most severely in E2-T and S1-A. After a single slight rise early in the test, the weight of the scaled material in samples Ref-A and E3-T flattened.

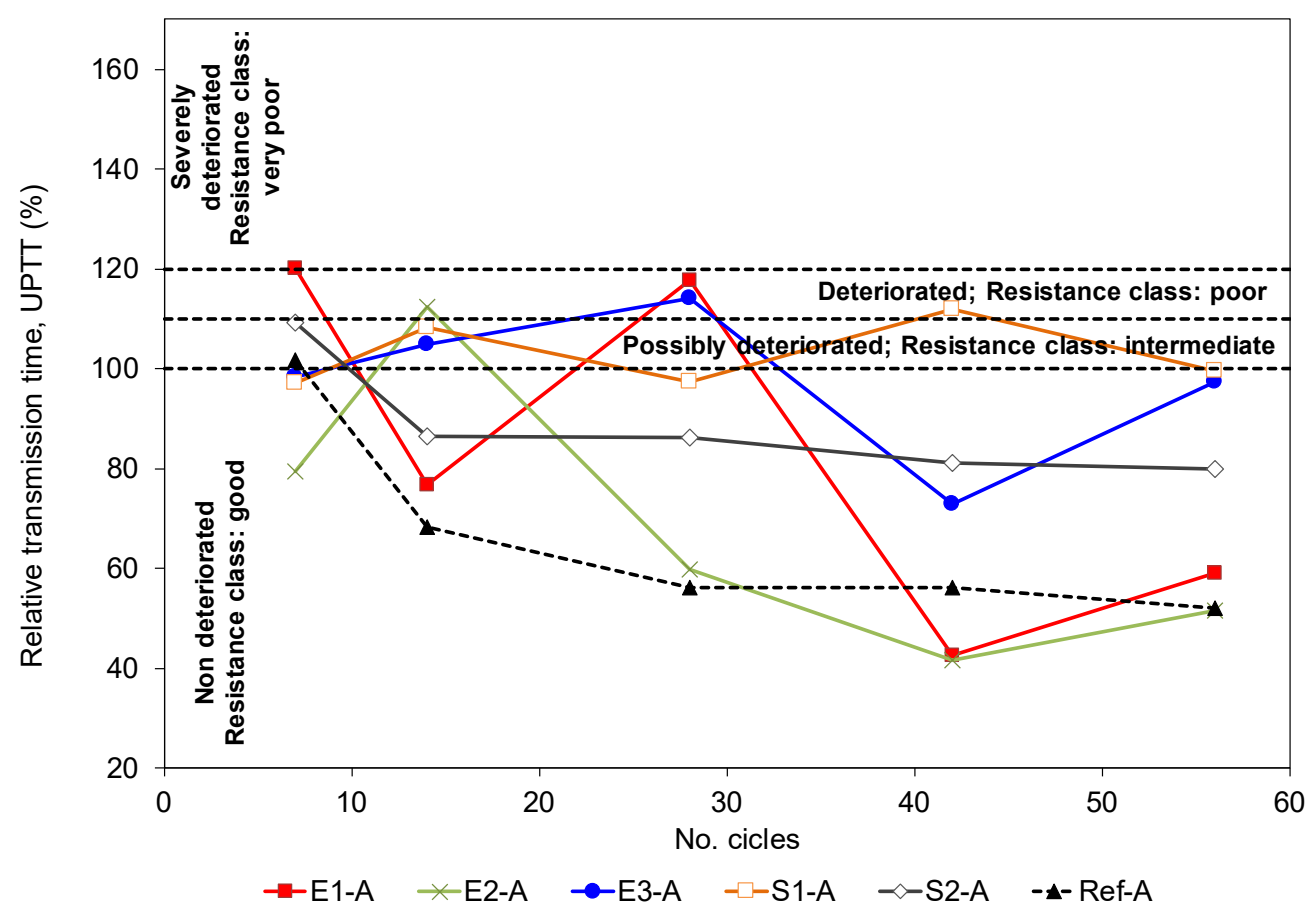

(a)

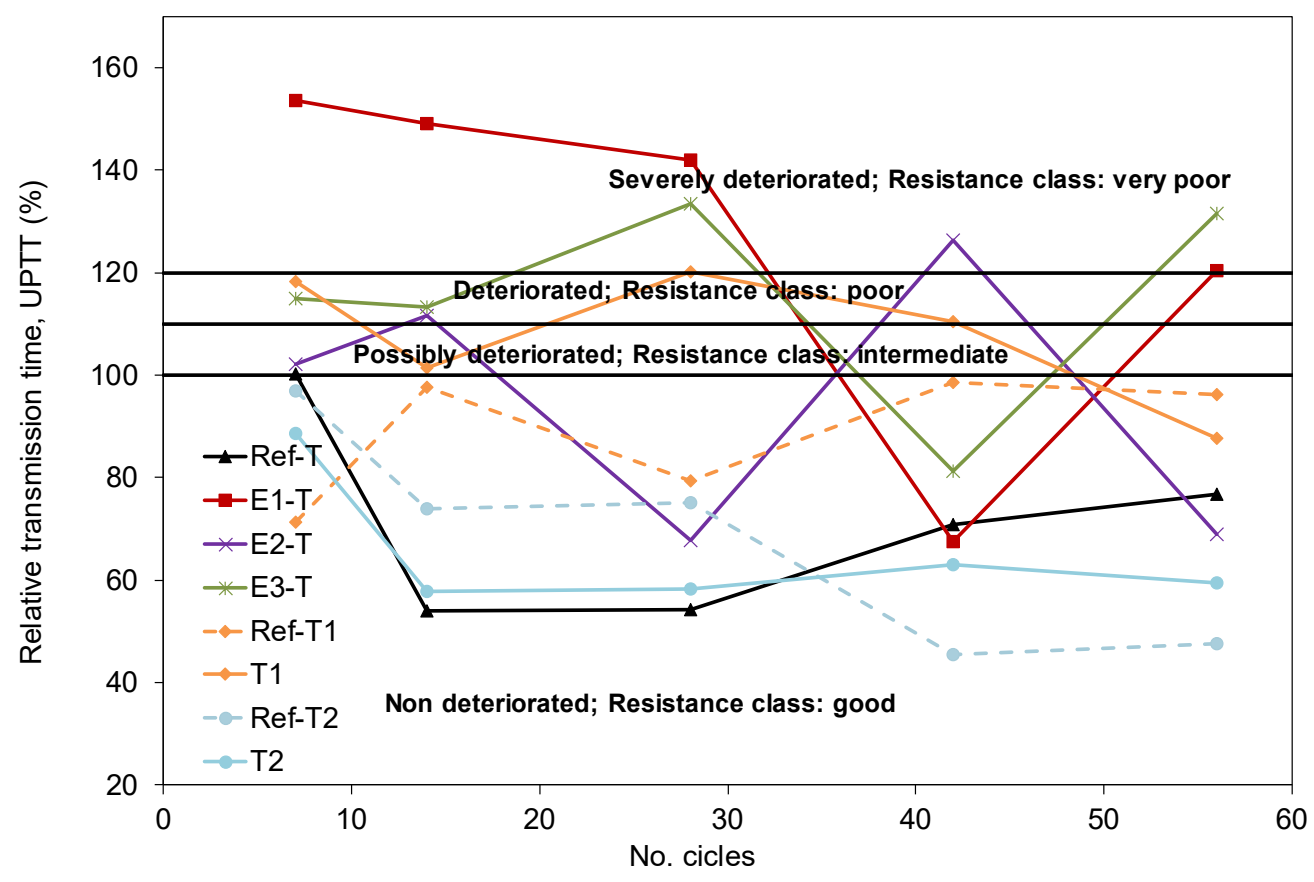

(b)

Figure 4. (a) Relative UPTT (\%) in all (a) asphalt and (b) paving tile samples. 


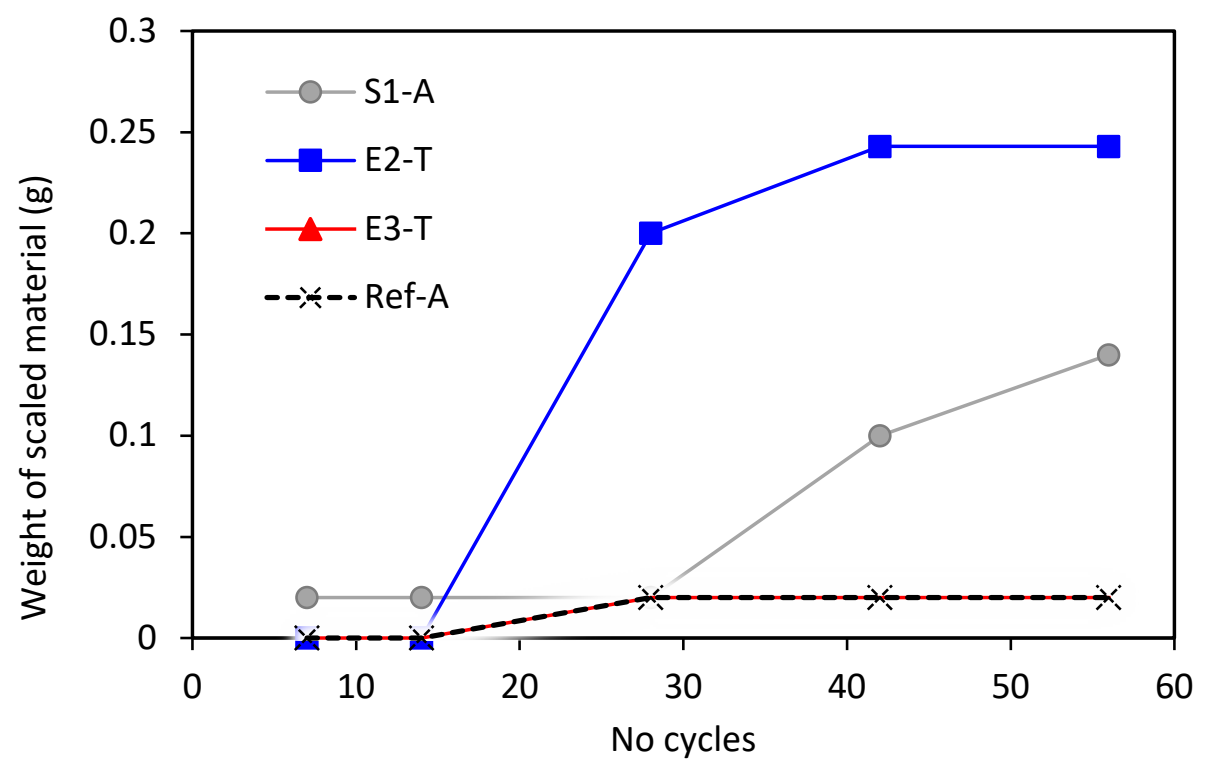

Figure 5. Weight of scaled material in selected samples.

Even to the naked eye, the photographs of the photocatalytic specimens reproduced in Figure 6 clearly revealed that the coatings had worn away after freeze-thaw testing. When the asphalt was coated, the samples initially turned light grey, whilst after the cycles the colour reverted to the original black. The same effect was observed on the paving tiles, although the difference was less dramatic. The slurries also disappeared from the surface, especially in sample S2-A, in which the pre-test whiteness vanished, unveiling the black asphalt across the entire surface after the cycles.

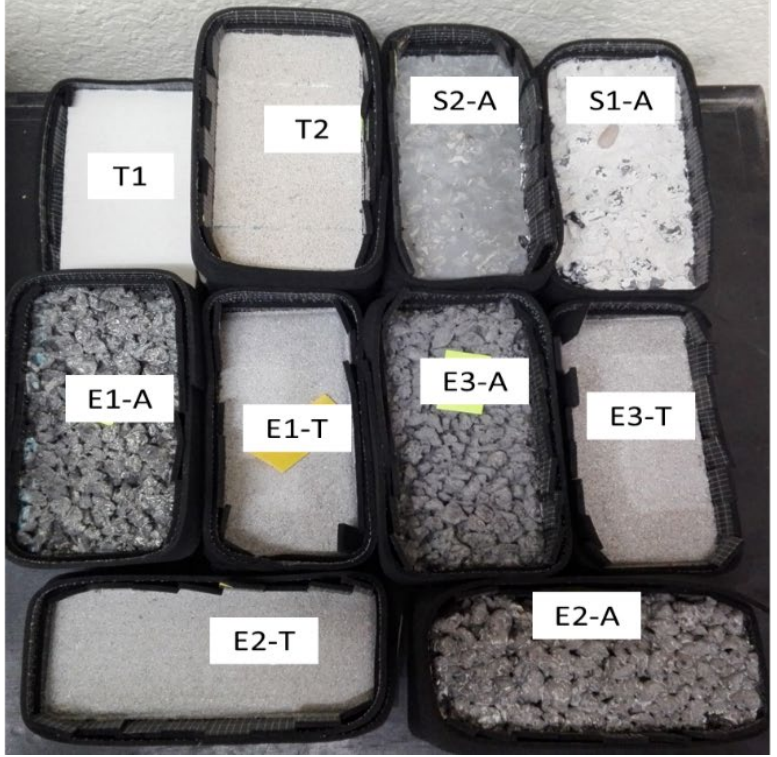

(a)

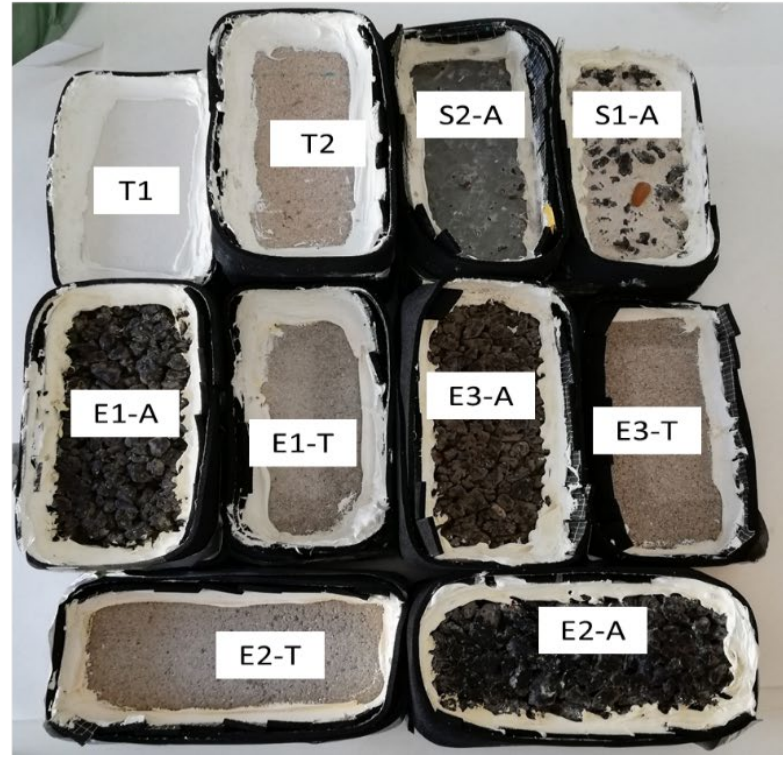

(b)

Figure 6. Photocatalytic specimens (a) before and (b) after the freeze-thaw test.

The optical micrographs in Figure 7 show that in addition to the change in colour, the slurry-based samples, showed some cracks, whilst the white photocatalytic layer was missing altogether in the emulsion-coated materials. Most of the samples bore an obvious resemblance to the reference materials. 


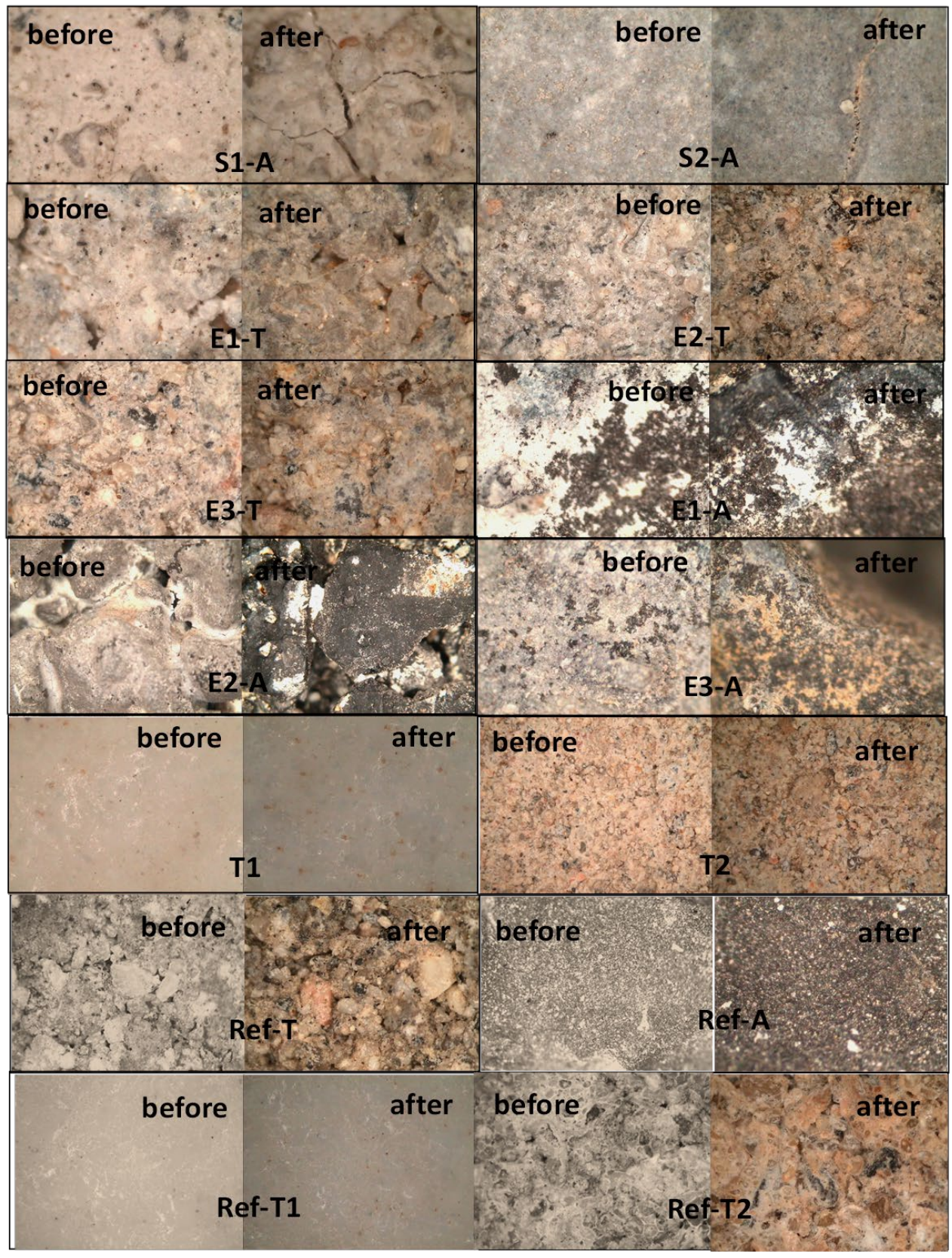

Figure 7. Optical micrographs ( $\times 3$ magnifications) of the photocatalytic samples before and after the freeze-thaw trials.

\subsection{Capillary Water Absorption}

The water absorption curve for specimen E2-T in Figure 8, reproduced by way of example, can be clearly divided into two areas (intake and saturation). The intersection between the two is marked on the graph. 


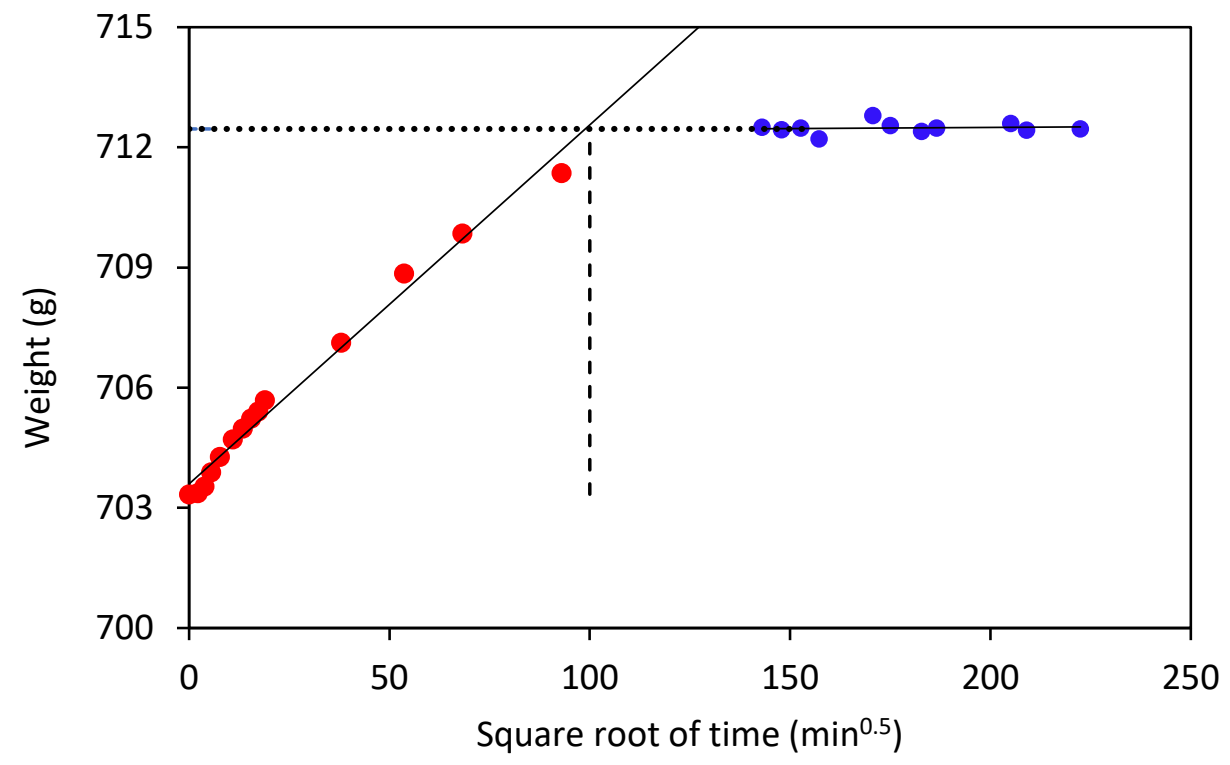

Figure 8. Water absorption curve for specimen E2-T.

The percentage absorbed by the photocatalytic materials less the percentage recorded for the respective references is depicted in Figure 9. Curves lying above zero denote greater absorption by the photocatalytic material than the reference and vice-versa. The absorption parameters for all the materials are summarised in Figure 10: effective porosity, $\varepsilon_{e}$, in Figure 10a and the capillary absorption coefficient, $k\left(\mathrm{~kg} / \mathrm{m}^{2} \mathrm{~min}^{0.5}\right)$, in Figure 10b.

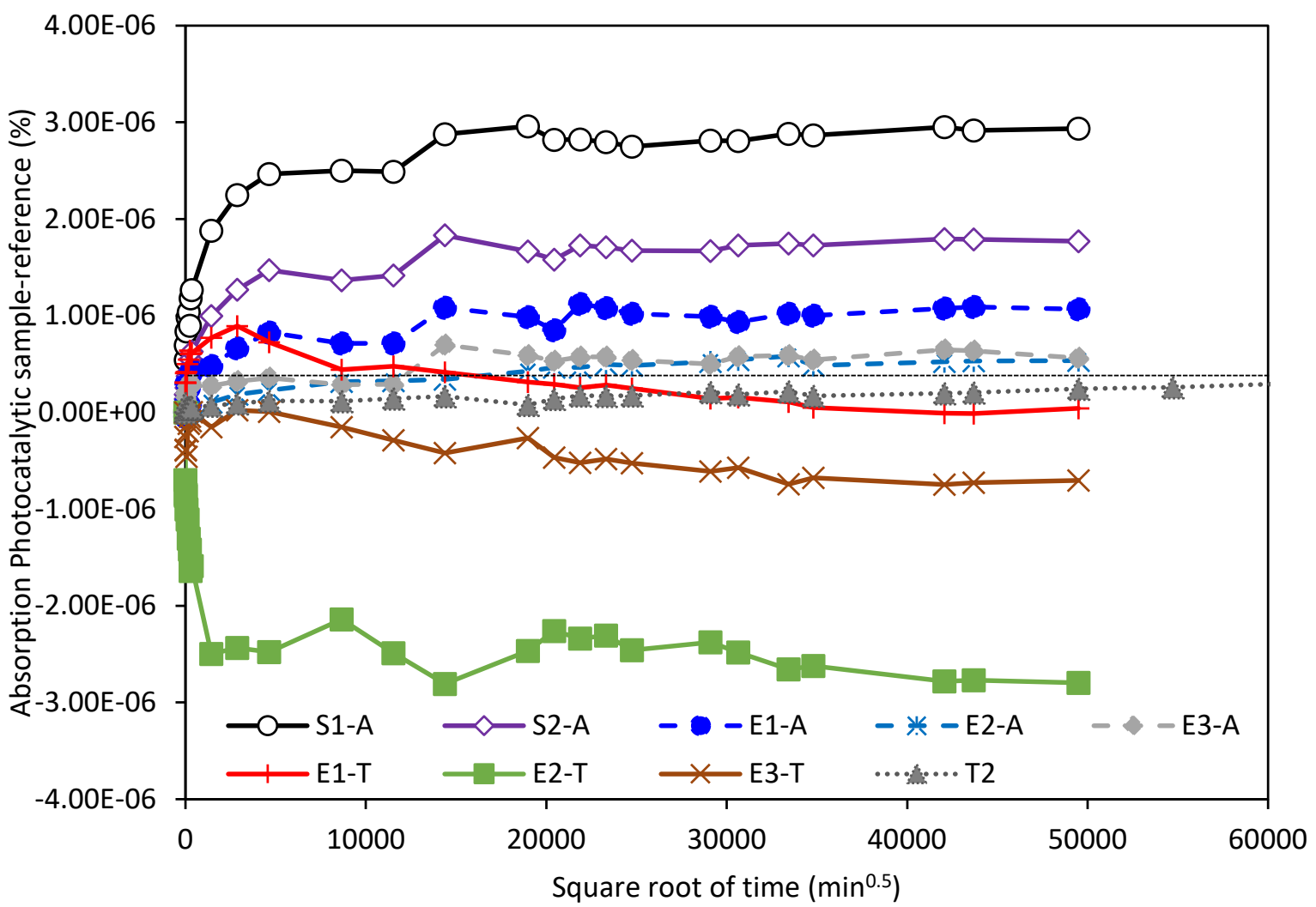

Figure 9. Percentage of water absorbed by the photocatalytic materials less absorption by the respective references. 

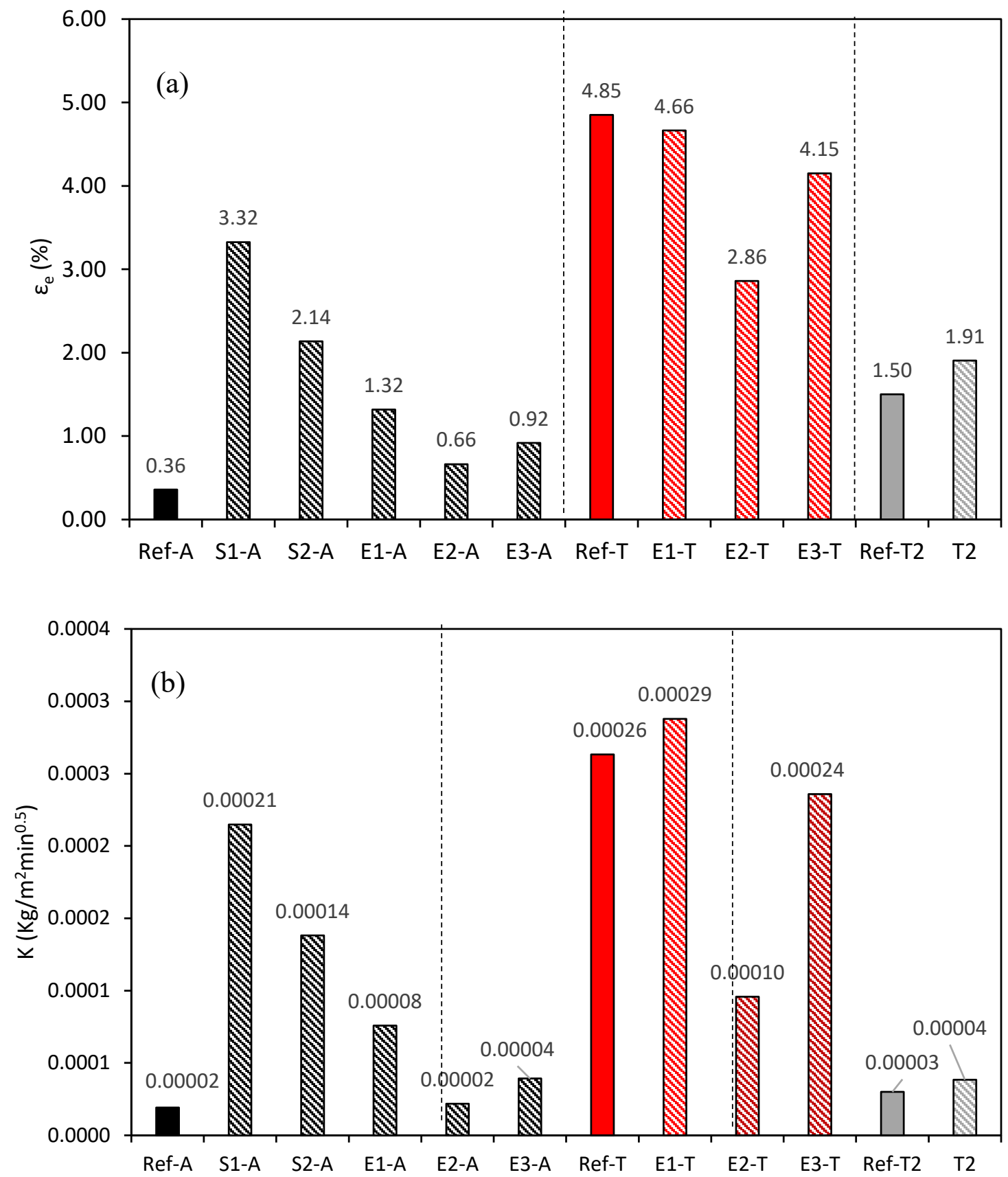

Figure 10. (a) Effective porosity $\left(\varepsilon_{e}\right)$, and (b) capillary absorption coefficient $(k)$ for all the samples studied.

Figures 9 and 10 show that the use of photocatalytic slurries raised the amount of water absorbed by specimens S1-A and S2-A relative to Ref-A. The change in behaviour induced by emulsion coatings clearly depended on the type of $\mathrm{TiO}_{2}$ photocatalytic material: emulsion E2 was the most resistant to water penetration both in asphalt and in paving tiles (E2-A and E2-T), being E1 the least resistant. Concerning sample T2, the differences between photocatalytic and reference samples are not significant.

\subsection{Slip Resistance and Roughness}

The slip resistance $\left(S_{R}\right)$ findings delivered by the pendulum tester are graphed in Figure 11. No meaningful differences were detected between the asphalt mix containing photocatalytic slurry S1 (S1-A) and the asphalt reference sample (Ref-A). In contrast, slip resistance declined significantly in asphalt mix S2-A relative to the reference. Resistance was slightly lower in emulsion-coated asphalts E1-A to E3-A than in the reference sample. 
$S_{R}$ values were slightly higher in all the photocatalytic paving tiles, whether coated (E1-T to E3-T) or built-in (T1 and T2) than in their respective references.

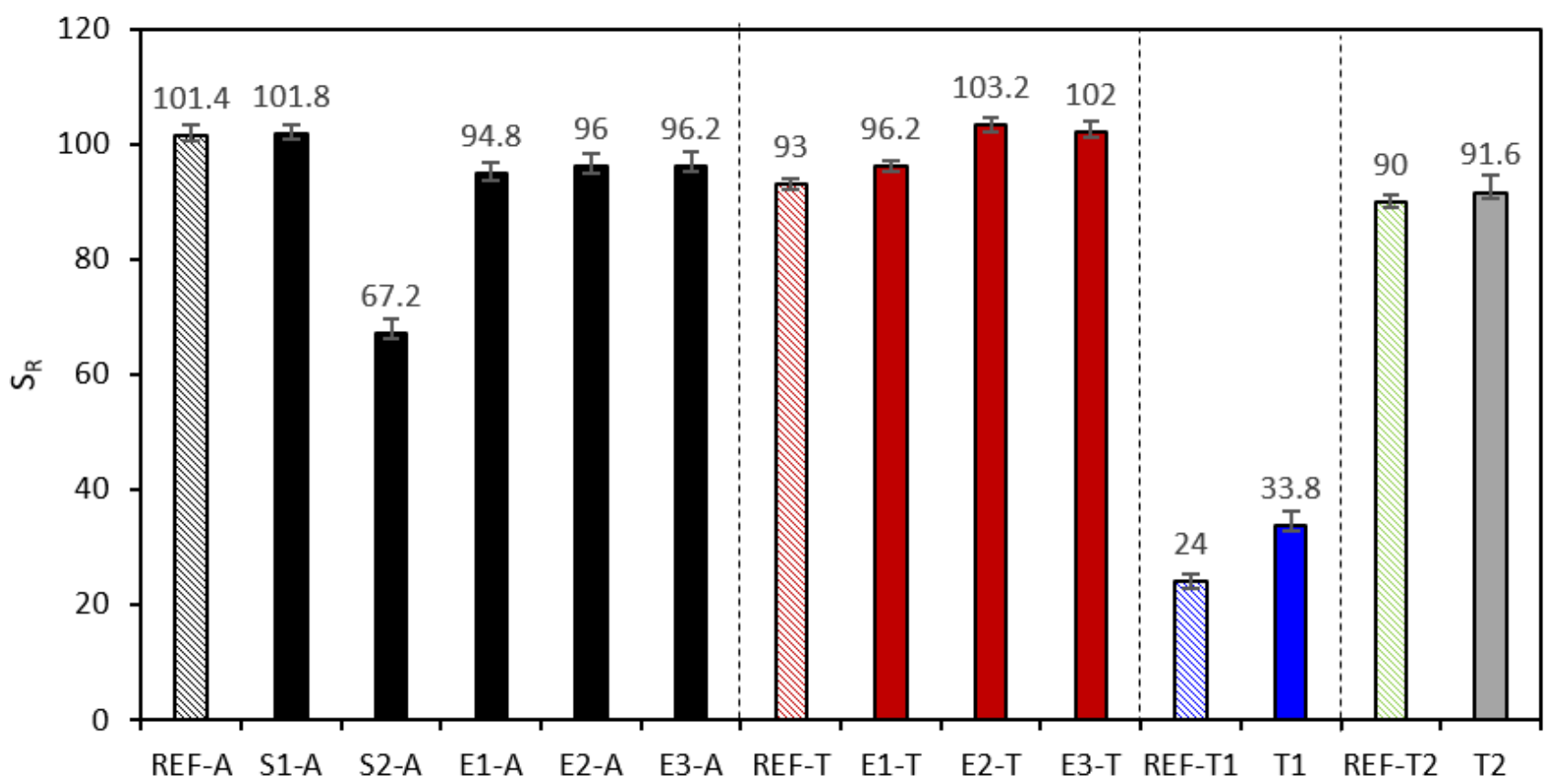

Figure 11. Slip resistance values $\left(S_{R}\right)$ for the materials studied.

The surface profiles for samples Ref-A and S2-A generated from photos with ImageJ software are reproduced in Figure 12. The figure reveals the obvious difference between surfaces for the plain asphalt (Ref-A) and sample S2-A, where slurry S2 filled the voids, generating a smooth surface.
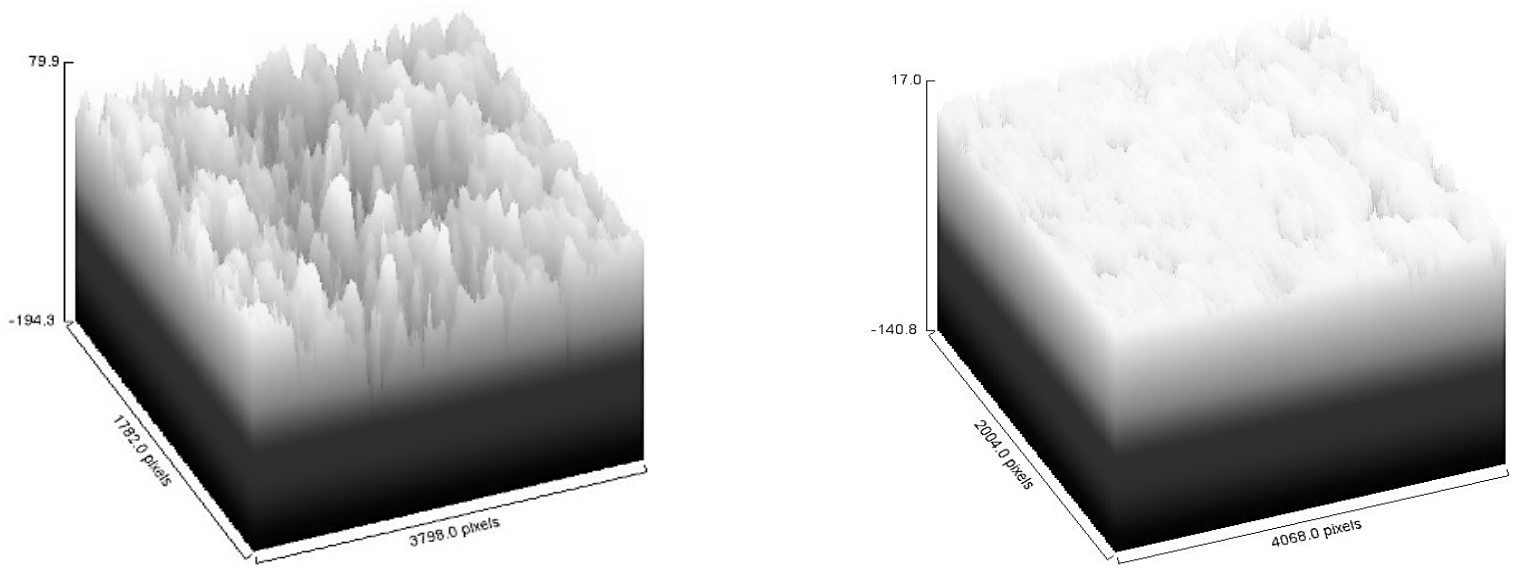

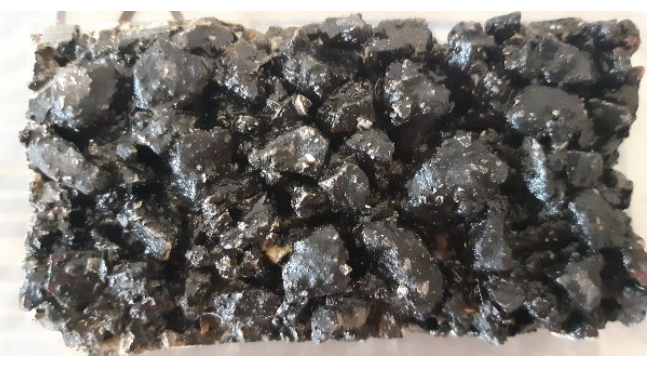

(a) Ref-A

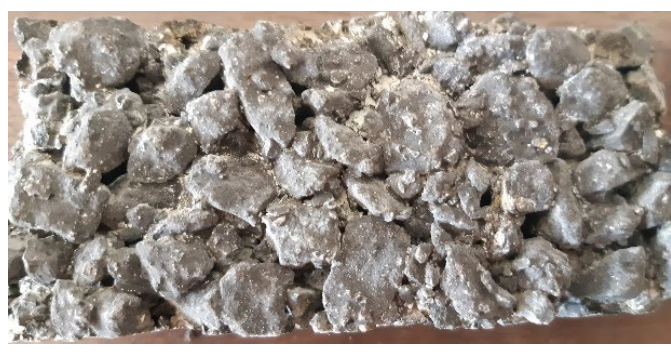

(b) S2-A

Figure 12. 3D roughness profiles and images for (a) reference asphalt (Ref-A) and (b) photocatalytic slab S2-A. 
The profiles were subsequently translated into $R a$ (pixels), a parameter that characterises surface roughness. The respective values are shown in Figure 13 for all the materials studied. The most significant effect was the decline in roughness in the slurry-bearing porous asphalt materials. $R a$ is plotted against $S_{R}$ in Figure 14. Further to the findings, slip resistance rose with roughness only in the samples with low roughness values $(\operatorname{Ra}<13)$, after which it remained flat. That apparent discrepancy may be attributable to the limited applicability of pendulum testers to rough surfaces [56]. The $S_{R}$ values observed for the rougher samples $(R a>13)$ must therefore be interpreted with caution.

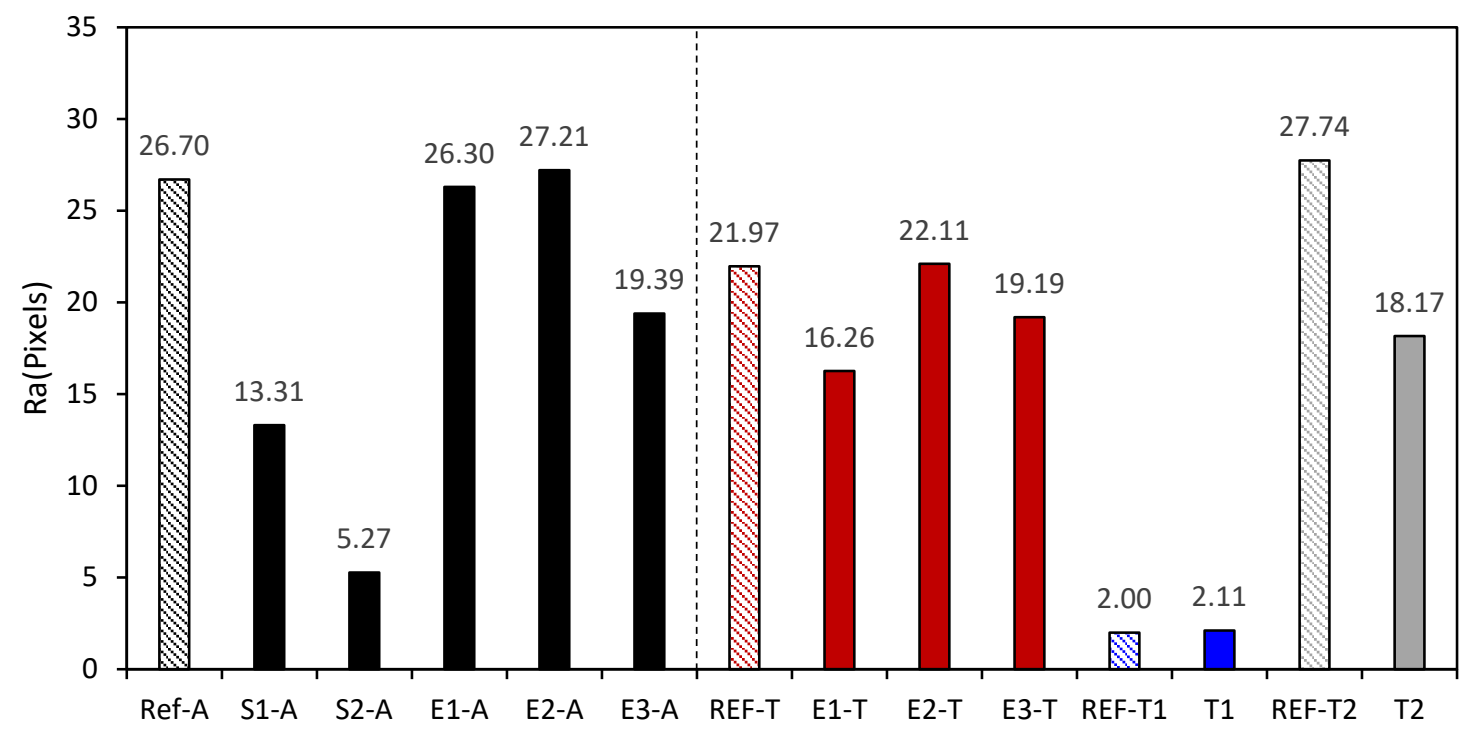

Figure 13. Surface roughness, $R a$ (pixels), for all the materials studied.

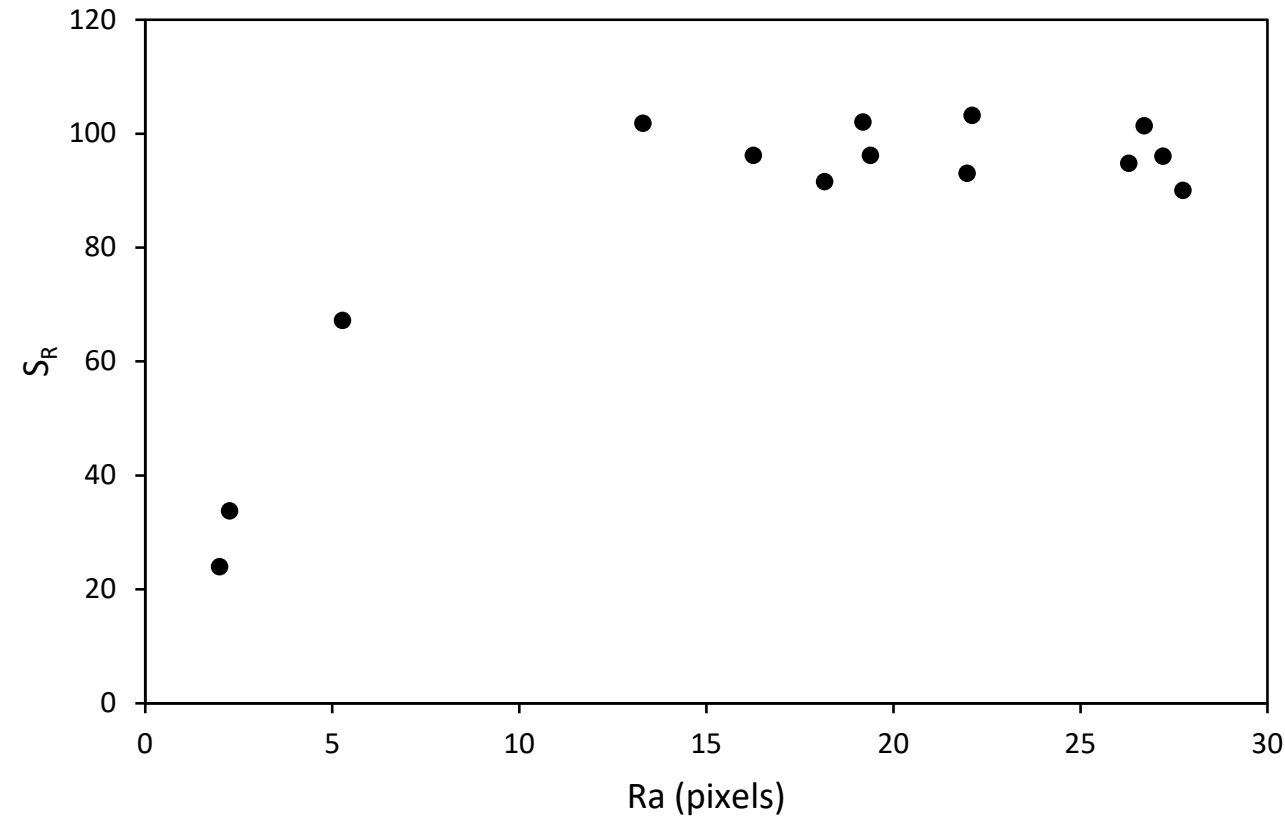

Figure 14. Slip resistance $\left(S_{R}\right)$ measured by a pendulum tester (standard EN-14231) versus surface roughness, $R a$.

\section{Discussion}

Table 6 summarises the major findings of this study, expressed as the percentage variation in each photocatalytic-treated material relative to its reference. The beneficial effects for durability or safety of adding $\mathrm{TiO}_{2}$ to the materials are shaded in green and un- 
derlined, whereas the adverse effects are shaded in red with a bold typeface. Even though this a rough simplification, shorter ultrasound transmission time, less effective porosity and a smaller capillary absorption coefficient were deemed to be beneficial, whilst lower slip resistance and roughness values were regarded as adverse. No shading means that the experimental material and the reference exhibited approximately the same behaviour (difference $= \pm 10 \%$ ).

Table 6. Summary of findings for photocatalytically treated material.

\begin{tabular}{|c|c|c|c|c|c|c|c|}
\hline \multirow{2}{*}{$\begin{array}{c}\text { Sample } \\
\text { S1-A }\end{array}$} & \multirow{2}{*}{$\begin{array}{c}\text { Freeze-Thaw Resistance } \\
\text { [52] } \\
\text { Intermediate }\end{array}$} & \multicolumn{2}{|c|}{$\begin{array}{c}\text { Ultrasounds } \\
\Delta t(\%) \\
\text { Cores Slabs }\end{array}$} & \multicolumn{2}{|c|}{$\begin{array}{l}\text { Intake of Water } \\
\Delta \varepsilon_{e}(\%) \Delta k(\%)\end{array}$} & \multicolumn{2}{|c|}{$\begin{array}{c}\text { Slip Resistance } \\
\Delta S_{R}(\%) \Delta R a(\%)\end{array}$} \\
\hline & & $\underline{46.3}$ & $\underline{11.7}$ & -825 & -1020 & -0.39 & 50.16 \\
\hline S2-A & Good & $\underline{66.0}$ & $\underline{42.5}$ & -494 & -619 & 33.73 & 80.26 \\
\hline E1-A & Good & -23.1 & -6.1 & -267 & -295 & 6.51 & 1.52 \\
\hline E2-A & Good & -8.2 & 14.3 & -85 & -14 & 5.33 & -1.90 \\
\hline E3-A & Intermediate/Good & -50.6 & -77.7 & -156 & -104 & 5.13 & 27.38 \\
\hline E1-T & Poor/Very poor & $\underline{32.4}$ & -45.9 & 4 & -9 & -3.44 & 25.98 \\
\hline $\mathrm{E} 2-\mathrm{T}$ & Poor & $\underline{21.8}$ & -40.0 & $\underline{41}$ & $\underline{64}$ & -10.97 & -0.62 \\
\hline E3-T & Poor & $\underline{25.0}$ & -30.9 & $\underline{14}$ & $\underline{10}$ & -9.68 & 12.63 \\
\hline $\mathrm{T} 1$ & Intermediate/Poor & $\underline{18.8}$ & 38.2 & ----- & ------ & $\overline{-10.83}$ & -5.74 \\
\hline $\mathrm{T} 2$ & Good & -9.9 & -51.2 & -27 & -28 & -1.78 & 34.52 \\
\hline
\end{tabular}

Note: green shaded cells, values underlined: better performance than the respective reference; red shaded cells, values in bold typeface: poorer performance than the respective reference; unshaded cells: approximately the same performance as the reference ( $\pm 10 \%$ difference).

These findings preclude any sweeping statement on the variation in durability and slip-safety of construction materials after photocatalytic treatment. The effect of adding $\mathrm{TiO}_{2}$-based photocatalysts on the durability of the substrates analysed here does not seem to be related to the photocatalytic properties themselves but derived mainly from the physical effect of the addition of a coating to the material, the inclusion of a filler in the mass of the tiles, or to the effect of compaction of the asphalt in the case cementitious slurries, with the resulting changes in the pore structure and surfaces of the matrixes.

Pore structure is related to liquid and gas transport in porous solids. In damp environments, one of the forces driving aggressive agent ingress is the capillary absorption resulting from the surface tension generated in capillary pores. Absorption, which is related not only to pore structure but also to sample moisture, is a significant durability indicator. The amount of water that can be absorbed is determined by effective porosity (capillary and gel pores). Air voids, in turn, which adsorb the increase in volume induced by freezing water, are beneficial in the event of frost. Indeed, entrained air is one of the approaches for enhancing concrete freeze-thaw resistance. Unlike capillary pores, large air voids do not contribute to capillary absorption.

In the materials containing slurries, the ultrasound transmission time was shorter in both the slabs and the cores than in the respective references, signifying greater compaction and mechanical strength, for the slurries filled the air voids in the asphalt. As a consequence, instead of drain water, it remains retained in the capillary porous structure of the slurry, increasing uptake of water and therefore, the effective porosity and coefficient of capillary absorption. Due to filling of the voids, roughness decreases greatly, which is not detected by the slip resistance measured by the pendulum in the case of S1-A. Whilst effect on freeze-thaw performance varied with the material: S2-A lay in the 'good' range and S1-A in the next lower category, in keeping with its greater water intake.

Emulsion-sprayed asphalt resisted frost well, as expected, although its mechanical strength was not enhanced leading to similar ultrasound times and slip resistance. Similarly, the smaller mean pore diameter induced by the emulsions raised water intake to the detriment of durability.

In the paving tiles, the $\mathrm{TiO}_{2}$-based emulsions generated a more refined pore system on the tile surface, with a predominance of mesopores. The direction of the variation in ultrasound transmission time relative to the reference differed in the paving tile slabs and the cores in all three emulsions. In the cores, where the readings were taken with 
the transducers spaced at $4 \mathrm{~cm}$ (initial data for freeze-thaw tests), the time was shorter than in the reference, inferring that the former material was more compact and homogeneous. Conversely, UPTT was longer in the photocatalytic than in the reference slabs. This discrepancy has been attributed to the difference in transducer spacing. When the sensors were very close, the signal travelled across the continuous, compact layers of the emulsion, whereas when they were spaced farther apart, the likelihood of finding discontinuities in the photocatalytic layer is higher. In the latter setup the ultrasonic waves would penetrate the concrete, crossing the photocatalytic layer-substrate interface twice. A schema explaining this difference is given in Figure 15. Further to that premise, the decline in freeze-thaw resistance observed in all the E-T materials could be attributed to deterioration in the photocatalytic layer only whilst tile integrity would remain unaffected, a postulate consistent with the optical microscope findings. Capillary porosity accessible to water would also decline, raising the resistance to water penetration, especially in E2-T and E3-T, as borne out by the MIP values. Although the pendulum tester showed a pattern of higher slip resistance, no general trend could be determined for surface roughness in the emulsion-coated paving tiles.

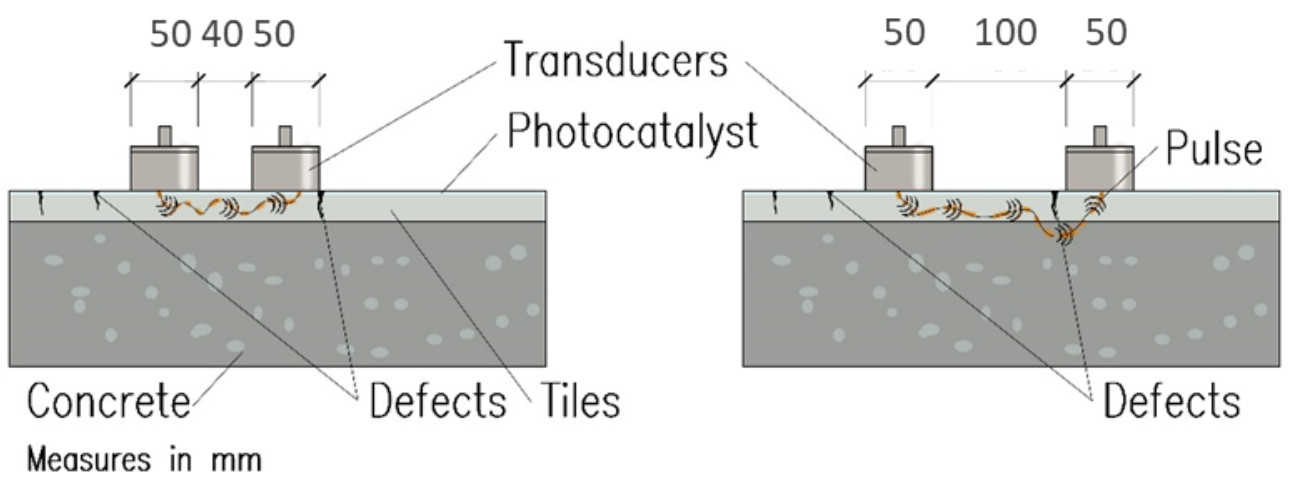

Figure 15. Schema of ultrasonic pulse travel in $15 \times 8 \mathrm{~cm}$ core specimens and whole slabs with differently spaced transducers.

The differences between the intrinsic characteristics of built-in photocatalyst paving tiles T1 and T2 determined visible differences in their behaviour. Dense, compact T1 had no air voids and scantly any capillary porosity. With the inclusion of a photocatalyst its durability-related properties remained unaltered or varied slightly and for the better with one exception. Its freeze-thaw resistance declined, a finding consistent with the delamination of the photocatalytic surface observed in the freeze-thaw test. Conversely, in paving tile $\mathrm{T} 2$ the photocatalyst had an adverse effect on all the parameters indicative of durability except freeze-thaw resistance, which has been attributed to the increase in the air porosity of the photocatalytic sample.

\section{Conclusions}

The impact of three types of $\mathrm{TiO}_{2}$ photocatalysts (slurries emulsions, and built-in) on the durability and safety of pavements (tiles and asphalts) has been studied. According to the results, the effects do not seem to be related to the photocatalytic properties themselves but derived mainly from the physical effects of the additions. The slurry solutions on the open-grade asphalt increase the mechanical strength by compacting the asphalt substrate. This filling implies a reduction in surface roughness, which could lead to a decrease in slip resistance. Capillary pores in the cementitious paste were introduced, resulting in an increase in water intake by capillary absorption and reduction of the resistance to freeze-thaw. Photocatalytic emulsions sprayed on pavements should not be detrimental to the freeze-thaw resistance of the substrate itself, although most of the photocatalytic layer would be worn away or damaged in the process. A compact photocatalytic coating reduces capillary porosity accessible to water and consequently raises the resistance to water ingress if it converts the large capillary pores in the matrix into small capillary pores, 
refining porosity. In contrast, if it generates more capillary pores than initially present, water intake increases. The behaviour of the tiles with built-in photocatalysts is dependent on their differences between their physical-chemical characteristics, loading and mode of implementation. These results indicate the importance of carrying out specified studies of the pavements prior to the application of photocatalytic solutions.

Author Contributions: Test development: M.G.; Conceptualization, M.C.; methodology, M.C.; software, F.R.; validation, M.C. and E.J.-R.; formal analysis M.C. and E.J.-R.; data curation, E.J.-R. and M.C.; writing—original draft preparation, M.C. and E.J.-R.; writing—review and editing, M.C. and E.J.-R.; supervision, M.C. and E.J.-R.; project administration, M.C.; funding acquisition, M.C. All authors have read and agreed to the published version of the manuscript.

Funding: This study was co-funded by the LIFE programme (LIFE PHOTOSCALING, LIFE 13/ENV/ ES/001221, http://www.life-photoscaling.eu/).

Institutional Review Board Statement: Not applicable.

Informed Consent Statement: Not applicable.

Data Availability Statement: Not applicable.

Acknowledgments: The authors wish to thank the manufacturers for supplying the photocatalytic products used.

Conflicts of Interest: The authors declare no conflict of interest.

\section{References}

1. Fujishima, A.; Honda, K. Electrochemical photolysis of water at a semiconductor electrode. Nature 1972, 238, 37. [CrossRef] [PubMed]

2. Wrighton, M.S.; Ellis, A.B.; Wolczanski, P.T.; Morse, D.L.; Abrahamson, H.B.; Ginley, D.S. Strontium titanate photoelectrodes. Efficient photoassisted electrolysis of water at zero applied potential. J. Am. Chem. Soc. 1976, 98, 2774-2779. [CrossRef]

3. Folli, A.; Jakobsen, U.; Guerrini, G.; Macphee, D. Rhodamine B discolouration on $\mathrm{TiO}_{2}$ in the cement environment: A look at fundamental aspects of the self-cleaning effect in concretes. J. Adv. Oxid. Technol. 2009, 12, 126-133. [CrossRef]

4. Peruchon, L.; Puzenat, E.; Herrmann, J.; Guillard, C. Photocatalytic efficiencies of self-cleaning glasses. Influence of physical factors. Photochem. Photobiol. Sci. 2009, 8, 1040-1046. [CrossRef]

5. Folli, A.; Pade, C.; Hansen, T.B.; De Marco, T.; Macphee, D.E. $\mathrm{TiO}_{2}$ photocatalysis in cementitious systems: Insights into self-cleaning and depollution chemistry. Cem. Concr. Res. 2012, 42, 539-548. [CrossRef]

6. Diamanti, M.; Del Curto, B.; Ormellese, M.; Pedeferri, M. Photocatalytic and self-cleaning activity of colored mortars containing $\mathrm{TiO}_{2}$. Constr. Build. Mater. 2013, 46, 167-174. [CrossRef]

7. Bengtsson, N.; Castellote, M. Heterogeneous photocatalysis on construction materials: Effect of catalyst properties on the efficiency for degrading NOx and self cleaning. Mater. Construcción 2014, 64, 13. [CrossRef]

8. Cassar, L. Photocatalysis of cementitious materials: Clean buildings and clean air. MRS Bull. 2004, 29, 328-331. [CrossRef]

9. Chen, J.; Poon, C.-s. Photocatalytic cementitious materials: Influence of the microstructure of cement paste on photocatalytic pollution degradation. J. Environ. Sci. Technol. 2009, 43, 8948-8952. [CrossRef]

10. Hüsken, G.; Hunger, M.; Brouwers, H. Experimental study of photocatalytic concrete products for air purification. J. Build. Environ. 2009, 44, 2463-2474. [CrossRef]

11. Bengtsson, N.; Castellote, M. Photocatalytic Activity for NO Degradation by Construction Materials: Parametric Study andMultivariable Correlations. J. Adv. Oxid. Technol. 2010, 13, 341-349. [CrossRef]

12. Dillert, R.; Engel, A.; Große, J.; Lindner, P.; Bahnemann, D.W. Light intensity dependence of the kinetics of the photocatalytic oxidation of nitrogen (ii) oxide at the surface of $\mathrm{TiO}_{2}$. J. Phys. Chem. Chem. Phys. 2013, 15, 20876-20886. [CrossRef]

13. Jimenez-Relinque, E.; Castellote, M. Influence of the inlet air in efficiency of photocatalytic devices for mineralization of VOCs in air-conditioning installations. Environ. Sci. Pollut. Res. 2014, 21, 11198-11207. [CrossRef]

14. Jiménez-Relinque, E.; Hingorani, R.; Rubiano, F.; Grande, M.; Castillo, Á.; Castellote, M. In situ evaluation of the NOx removal efficiency of photocatalytic pavements: Statistical analysis of the relevance of exposure time and environmental variables. Environ. Sci. Pollut. Res. 2019, 26, 36088-36095. [CrossRef]

15. Goswami, D.; Trivedi, D.; Block, S. Photocatalytic disinfection of indoor air. J. Sol. Energy Eng. 1997, 119, 92-96. [CrossRef]

16. Sikora, P.; Cendrowski, K.; Markowska-Szczupak, A.; Horszczaruk, E.; Mijowska, E. The effects of silica/titania nanocomposite on the mechanical and bactericidal properties of cement mortars. J. Constr. Build. Mater. 2017, 150, 738-746. [CrossRef]

17. Cannavale, A.; Fiorito, F.; Manca, M.; Tortorici, G.; Cingolani, R.; Gigli, G.J.B. Environment Multifunctional bioinspired sol-gel coatings for architectural glasses. J. Build. 2010, 45, 1233-1243. [CrossRef] 
18. Sapiña, M.; Jimenez-Relinque, E.; Castellote, M. Controlling the levels of airborne pollen: Can heterogeneous photocatalysis help? J. Environ. Sci. Technol. 2013, 47, 11711-11716. [CrossRef]

19. Jimenez-Relinque, E.; Sapiña, M.; Nevshupa, R.; Roman, E.; Castellote, M. Photocatalytic decomposition of pollen allergenic extracts of Cupressus arizonica and Platanus hybrida. Chem. Eng. J. 2016, 286, 560-570. [CrossRef]

20. Sapiña, M.; Jimenez-Relinque, E.; Nevshupa, R.; Roman, E.; Castellote, M. Degradation of pollen on nanofunctionalized photocatalytic materials. J. Chem. Technol. Biotechnol. 2017, 92, 210-216. [CrossRef]

21. Sapiña, M.; Jimenez-Relinque, E.; Roman, E.; Nevshupa, R.; Castellote, M. Unusual photodegradation reactions of Asteraceae and Poaceae grass pollen enzymatic extracts on P25 photocatalyst. Environ. Sci. Pollut. Res. 2021, 28, 24206-24215. [CrossRef]

22. Smits, M.; kit Chan, C.; Tytgat, T.; Craeye, B.; Costarramone, N.; Lacombe, S.; Lenaerts, S. Photocatalytic degradation of soot deposition: Self-cleaning effect on titanium dioxide coated cementitious materials. J. Chem. Eng. J. 2013, 222, 411-418. [CrossRef]

23. Zhu, W.; Bartos, P.J.; Porro, A. Application of nanotechnology in construction. Mater. Struct. 2004, 37, 649-658. [CrossRef]

24. Pacheco-Torgal, F.; Jalali, S.J.C. Nanotechnology: Advantages and drawbacks in the field of construction and building materials. J. Constr. Build. Mater. 2011, 25, 582-590. [CrossRef]

25. Jayapalan, A.R.; Lee, B.Y.; Kurtis, K.E. Can nanotechnology be 'green'? Comparing efficacy of nano and microparticles in cementitious materials. Cem. Concr. Compos. 2013, 36, 16-24. [CrossRef]

26. Calia, A.; Lettieri, M.; Masieri, M. Durability assessment of nanostructured $\mathrm{TiO}_{2}$ coatings applied on limestones to enhance building surface with self-cleaning ability. J. Build. Environ. 2016, 110, 1-10. [CrossRef]

27. Jimenez-Relinque, E.; Grande, M.; Duran, T.; Castillo, Á.; Castellote, M. Environmental impact of nano-functionalized construction materials: Leaching of titanium and nitrates from photocatalytic pavements under outdoor conditions. Sci. Total Environ. 2020, 744, 140817. [CrossRef]

28. Yang, L.; Hakki, A.; Wang, F.; Macphee, D.E. Photocatalyst efficiencies in concrete technology: The effect of photocatalyst placement. J. Appl. Catal. B Environ. 2018, 222, 200-208. [CrossRef]

29. Graziani, L.; Quagliarini, E.; Bondioli, F.; D'Orazio, M.J.B. Durability of self-cleaning $\mathrm{TiO}_{2}$ coatings on fired clay brick façades: Effects of UV exposure and wet \& dry cycles. J. Build. Environ. 2014, 71, 193-203.

30. Hassan, M.M.; Dylla, H.; Mohammad, L.N.; Rupnow, T. Evaluation of the durability of titanium dioxide photocatalyst coating for concrete pavement. J. Constr. Build. Mater. 2010, 24, 1456-1461. [CrossRef]

31. Nevshupa, R.; Castellote, M.; Cornelio, J.A.C.; Toro, A. Triboemission of FINE and Ultrafine Aerosol Particles: A New Approach for Measurement and Accurate Quantification. Lubricants 2020, 8, 21. [CrossRef]

32. Nevshupa, R.; Jimenez-Relinque, E.; Grande, M.; Martinez, E.; Castellote, M. Assessment of urban air pollution related to potential nanoparticle emission from photocatalytic pavements. J. Environ. Manag. 2020, 272, 111059. [CrossRef] [PubMed]

33. Garciá, L.; Pastor, J.; Peña, J. Self cleaning and depolluting glass reinforced concrete panels: Fabrication, optimization and durability evaluation. J. Constr. Build. Mater. 2018, 162, 9-19. [CrossRef]

34. Mendoza, C.; Valle, A.; Castellote, M.; Bahamonde, A.; Faraldos, $\mathrm{M}$. $\mathrm{TiO}_{2}$ and $\mathrm{TiO}_{2}-\mathrm{SiO}_{2}$ coated cement: Comparison of mechanic and photocatalytic properties. Appl. Catal. B Environ. 2015, 178, 155-164. [CrossRef]

35. Wang, D.; Leng, Z.; Hüben, M.; Oeser, M.; Steinauer, B. Photocatalytic pavements with epoxy-bonded TiO ${ }_{2}$-containing spreading material. Constr. Build. Mater. 2016, 107, 44-51. [CrossRef]

36. Boonen, E.; Beeldens, A.; Dirkx, I.; Bams, V. Durability of Cementitious Photocatalytic Building Materials. Catal. Today 2017, 287, 196-202. [CrossRef]

37. Chen, J.; Kou, S.-c.; Poon, C.-s. Hydration and properties of nano-TiO 2 blended cement composites. Cem. Concr. Compos. 2012, 34, 642-649. [CrossRef]

38. Zhang, R.; Cheng, X.; Hou, P.; Ye, Z. Influences of nano- $-\mathrm{TiO}_{2}$ on the properties of cement-based materials: Hydration and drying shrinkage. Constr. Build. Mater. 2015, 81, 35-41. [CrossRef]

39. Meng, T.; Yu, Y.; Qian, X.; Zhan, S.; Qian, K. Effect of nano- $\mathrm{TiO}_{2}$ on the mechanical properties of cement mortar. Constr. Build. Mater. 2012, 29, 241-245. [CrossRef]

40. Nazari, A.; Riahi, S.; Riahi, S. Improvement the mechanical properties of the cementitious composite by using $\mathrm{TiO}_{2}$ nanoparticles. J. Am. Sci. 2010, 6, 98-101.

41. Lucas, S.S.; Ferreira, V.M.; de Aguiar, J.L.B. Incorporation of titanium dioxide nanoparticles in mortars-Influence of microstructure in the hardened state properties and photocatalytic activity. Cem. Concr. Res. 2013, 43, 112-120. [CrossRef]

42. Jimenez-Relinque, E.; Rodriguez-Garcia, J.; Castillo, A.; Castellote, M. Characteristics and efficiency of photocatalytic cementitious materials: Type of binder, roughness and microstructure. Cem. Concr. Res. 2015, 71, 124-131. [CrossRef]

43. Macphee, D.E.; Folli, A. Photocatalytic concretes-The interface between photocatalysis and cement chemistry. Cem. Concr. Res. 2016, 85, 48-54. [CrossRef]

44. Folli, A.; Pochard, I.; Nonat, A.; Jakobsen, U.H.; Shepherd, A.M.; Macphee, D.E. Engineering photocatalytic cements: Understanding $\mathrm{TiO}_{2}$ surface chemistry to control and modulate photocatalytic performances. J. Am. Ceram. Soc. 2010, 93, 3360-3369. [CrossRef]

45. Calvo, J.G.; Carballosa, P.; Castillo, A.; Revuelta, D.; Gutiérrez, J.; Castellote, M. Expansive concretes with photocatalytic activity for pavements: Enhanced performance and modifications of the expansive hydrates composition. Constr. Build. Mater. 2019, 218, 394-403. [CrossRef] 
46. Zhang, M.-H.; Li, H. Pore structure and chloride permeability of concrete containing nano-particles for pavement. Constr. Build. Mater. 2011, 25, 608-616. [CrossRef]

47. Fiore, A.; Marano, G.C.; Monaco, P.; Morbi, A. Preliminary experimental study on the effects of surface-applied photocatalytic products on the durability of reinforced concrete. J. Constr. Build. Mater. 2013, 48, 137-143. [CrossRef]

48. Attaur, R.; Qudoos, A.; Kim, G.H.; Ryou, J.-S. Influence of Titanium Dioxide Nanoparticles on the Sulfate Attack upon Ordinary Portland Cement and Slag-Blended Mortars. Materials 2018, 11, 356. [CrossRef]

49. Diamanti, M.V.; Lollini, F.; Pedeferri, M.P.; Bertolini, L. Mutual interactions between carbonation and titanium dioxide photoactivity in concrete. Build. Environ. 2013, 62, 174-181. [CrossRef]

50. Jimenez-Relinque, E.; Rubiano, F.; Hingorani, R.; Grande, M.; Castillo, A.; Nevshupa, R.; Castellote, M. A New Holistic Conceptual Framework for Assessment of Photocatalytic Pavements Performance. Front. Chem. 2020, 8, 743. [CrossRef]

51. Hingorani, R.; Jiménez-Relinque, E.; Grande, M.; Castillo, A.; Nevshupa, R.; Castellote, M.J.C.E.J. From analysis to decision: Revision of a multifactorial model for the in situ assessment of NOx abatement effectiveness of photocatalytic pavements. Chem. Eng. J. 2020, 402, 126250. [CrossRef]

52. Recommendation, F. Slab test: Freeze/thaw resistance of concrete-Internal deterioration. J. Draft Mater. Struct. 2001, 34, 526-531.

53. De Rincón, O.T.; Sánchez, M.; Millano, V.; Fernández, R.; de Partidas, E.; Andrade, C.; Martínez, I.; Castellote, M.; Barboza, M.; Irassar, F.J.C.S. Effect of the marine environment on reinforced concrete durability in Iberoamerican countries: DURACON project/CYTED. J. Corros. Sci. 2007, 49, 2832-2843. [CrossRef]

54. Chang, W.-R. The effect of surface roughness on the measurement of slip resistance. Int. J. Ind. Ergon. 1999, 24, 299-313. [CrossRef]

55. Lindseth, I.; Bardal, A. Quantitative topography measurements of rolled aluminium surfaces by atomic force microscopy and optical methods. Surf. Coat. Technol. 1999, 111, 276-286. [CrossRef]

56. Karaca, Z.; Gürcan, S.; Gökçe, M.V.; Sivrikaya, O.J.C. Assessment of the results of the pendulum friction tester (EN 14231) for natural building stones used as floor-coverings. J. Constr. Build. Mater. 2013, 47, 1182-1187. [CrossRef] 